\title{
LIKELIHOOD OF IMPACT EVENTS IN TRANSPORT NETWORKS CONSIDERING ROAD CONDITIONS, TRAFFIC AND ROUTING ELEMENTS PROPERTIES
}

\author{
Alfred STRAUSS ${ }^{*}$, Thomas MOSER ${ }^{2}$, Christian HONEGER ${ }^{2}$, \\ Panagiotis SPYRIDIS ${ }^{3}$, Dan M. FRANGOPOL ${ }^{4}$ \\ ${ }^{1}$ Department of Civil Engineering and Natural Hazards, University of Natural Resources \\ and Life Sciences, Vienna, Austria \\ ${ }^{2}$ Department of Asset Management, ASFINAG Service GMBH Vienna, Austria \\ ${ }^{3}$ Faculty of Architecture and Civil Engineering, TU Dortmund, Germany \\ ${ }^{4}$ Department of Civil and Environmental Engineering, ATLSS Engineering Research Center, \\ Lehigh University, Bethlehem, PA, USA
}

Received 28 May 2019; accepted 28 August 2019

\begin{abstract}
A large number of transport infrastructure equipment are located along the driving lanes of roadways, which must be secured by restraint systems. Among others, the different road lanes must be adequately separated from each other. The investigations reported herein aim to provide a probabilistic approach for the departure of motor vehicles from their intended lane and iimpact on restraint systems. Currently, evaluations of the road infrastructure against possible accidents are mostly focused on the resistance side. This contribution, however, intends to address the action side, focusing in particular on the probability of impact of vehicles on the road furniture. The main parameters taken into account are the geometry of the road and the traffic composition and characteristics. The objective of this research is to develop an analysis tool for the probability-based assessment of vehicles departing from their driving lane. The analysis tool for the determination of the likelihood of impact events in transport networks, requires to define (a) of the alignment (longitudinal inclination, transverse inclination, and curvature of the lanes), (b) of the pavement conditions (lane grooves, road grip, and pavement cracks etc.), and (c) of the traffic composition as significant input parameters. These were investigated together with the road infrastructure operators. A newly introduced methodology is presented herein taking into account the above mentioned parameters and factoring in characteristic properties in order to assess the fragility of the infrastructure subsystem. The evaluation is based on either road engineering physics or expert judgements. The method is incorporated in a spreadsheet tool, which is also presented, the feasibility of this tool is demonstrated, and sensitivities of the assessment process are evaluated and discussed.
\end{abstract}

Keywords: risk analysis, sensitivity, road conditions, routing elements.

\section{Introduction}

The growing number of deteriorating roads and bridges and the associated socioeconomic repercussions of their degraded performance capability have presented civil engineers with great challenges. Therefore, government bodies, highway owners and operators, and the industry in general, invest particular efforts in the maintenance and assessment of road infrastructure components (Strauss, Wendner, Bergmeister, Reiterer, \& Horvatits, 2011). To that end, the equipment of roads and bridges has gained significance, since they form a front line of safety against vehicle traffic-related accidents. These elements are inspected and investigated heavily, and their maintenance absorbs a significant portion of the assets' operational expenditures (Strauss, Vidovic, Zambon, Dengg, \& Matos 2016). This is also reflected in the fact that there is a large number of guidelines and regulatory standards addressing load models, design calculations, maintenance programs, inspection, recalculation, and lifetime and reliability assessment of existing components, such as provided by American Association of State Highway and Transpor-

*Corresponding author. E-mail: alfred.strauss@boku.ac.at 
tation Officials [AASHTO] (2018), Federal Ministry of Transportation, Building and Urban Development (2011), International Organization for Standardization [ISO] (2010), Nederlands Normalisatie Instituut (2011). Simultaneously, as discussed below, a considerable number of scientific investigations are centred around these considerations, based on risk and reliability concepts. These standards and research outcomes, however, lack a respective assessment concerning the likelihood and intensity of events and the interaction of road furniture with the traffic conditions (velocity, mixture of traffic), the surface conditions of lanes, and the routing elements of the lanes.

Hence the objective of the investigation presented in this paper is to develop a procedure that allows for a riskbased and significance-weighted evaluation for the performance assessment of road furniture due to the above influence factors. The reliability and risk concepts used in this study are in line with the fundamental texts of Ang and Tang (2007), and Schneider (2006). Reliability, expressed through reliability index $\beta$, is a measure of structural safety, representing the annual probability of failure for a given failure mode, in this case a vehicle departure from its lane and the associated impact event. Consequence of an impact is associated with loss of a single entity, since the assessment is based on the action side and not the damage resistance. As such, the risk in this framework is arithmetically translated to the likelihood of the impact event, following the fundamental definition of risk, by multiplying probability and consequence. A fragility curve in engineering can be considered as the assessment of the probability of exceeding a specific damage state according to the degradation process (see also Kim, 2018). The risk-based evaluation concept does not focus on the resistance side of furniture but rather on the action model that is highly variable. In particular, the detailed objectives are as follows:

- to develop together with an infrastructure owner an efficient analytical decision tool for the assessment and the intervention planning of the road equipment using elements of Probabilistic Safety Concepts (PSC);

- to combine traffic dynamic parameters and routing condition characteristics to a closed analytical solution for a RVS based rating of impacts on road equipment;

- to allow an individual adjustment of acceptable reliability levels, acceptable risks and thereby the remaining technical service life associated with the road equipment;

- to guarantee a user-friendly handling of input parameters characterized by numerous uncertainties affected from condition rating and physical fundamental laws;

- to support input of weak information e.g. from expert knowledge that can be improved with increasing time.
The model shown in this article is extensible for additional properties and can be transferred with relative flexibility to other systems based on large databases.

The investigations reported herein aim to provide a probabilistic approach for the departure of motor vehicles from their original lane. Currently, evaluations of the road infrastructure against possible accidents are always focused on the resistance side. This contribution, however, intends to address the impact side, focusing in particular on the probability of impact of a vehicle on road furniture.

In the immediate vicinity of the driving lanes, a large number of transport infrastructure equipment components are located along the route, which must be secured by restraint systems. In addition, the different road lanes must be adequately separated from each other. Through the implementation and assessment of different parameters, the probability of a vehicle's departure from the driving lane can be determined. The main parameters taken into account are the geometry of the road (longitudinal gradient, transverse gradient, radius of curvature), the condition of the road (ruts, grip, cracks, etc.) and the traffic composition (i.e. heavy goods vehicle proportion, Annual Average Daily Traffic - AADT/JDTV, Annual Average Daily Traffic volume of truck-like vehicles - AADTtlv/ JTDLV). The following work steps were carried out in the course of the project:

- Development of an evaluation procedure to determine the probability that a vehicle departs from its lane due to geometrical conditions;

- Development of an evaluation procedure to determine the probability that a vehicle departs from its lane due to traffic composition;

- Development of an evaluation procedure to determine the probability of a vehicle departing from its lane due to the road pavement condition;

- Development of an evaluation scheme and subsequently of a mitigation strategy;

- Implementation of the above points using a spreadsheet tool which allows an update and variation of all input parameters.

To the authors' best knowledge, previous research on the likelihood of lane departures in relation to the above mentioned parameters is essentially absent. A gap is evident in background literature and standards for the investigated components and in the context of this assessment, so inevitably the literature information is derived from technical systems with similar characteristics. As regards existing standard documents, an overview of the safety of road furniture can be gained from the "Guidelines and regulations for the road sector" (RVS) valid in Austria and the guidelines of the Austrian Technical Lighting Society (LTG) as regards the stability testing for support structures of lighting installations. The following Section 1 aims to provide an overview of existing procedures as a benchmark on the design and maintenance of related technical components. Finally, recent research projects as presented in Section 2 also provide useful information in this field. 


\section{Current standards}

Regarding structures that need to be designed against vehicle impact, the LTG Guideline for testing the stability of support structures of lighting installations, proposes adequate advice on visual inspection and testing layouts for the bending resistance, the cross sectional thickness, and eigenfrequency parameters for steel and concrete light poles. Furthermore, the RVS 08.09.02 "Surface protection of steel and aluminium" (Austrian Research Association for Roads, Railways and Transport - Österreichische Forschungsgesellschaft Straße-Schiene-Verkehr [FSV], 2007b) provides testing methods for lighting products and the light poles approval and acceptability, and the RVS 05.04.34 "Acceptance and test protocol for traffic light signal systems" (FSV, 1998b) provides the basis for test evaluation and categorization as positive / negative / not applicable (the latter is to be used in conjunction with RVS 05.04.33 (FSV, 1998a)). These two RVS guidelines apply for large overhead traffic sign structures but also for roadside vehicle restraint systems. RVS 13.03.51 "Monitoring, control and inspection of engineering structures signpost bridges" (FSV, 2013b) serves as a basis for the maintenance procedures for large overhead installations and related structures (e.g. traffic control systems, toll gantries). RVS 08.23.01 "Road equipment - Traffic sign tests" (FSV, 2009b) regulates the technical test criteria and test procedures for the certification of traffic signs, traffic sign carriers and fastening elements for small traffic signs. The RVS 05.02.11 "Traffic signs and advertisements - Requirements and specifications" (FSV, 2009a) regulates the production, assembly and erection of traffic signs at public roads, and in that sense, it also covers main elements of the structural design and dimensioning.

Focusing on roadside vehicle restraint systems, the applicable guidelines are, aside from RVS 08.09.02 (FSV, 2007b) and RVS 05.04.34 (FSV, 1998b), the RVS 08.23.05 "Road equipment - steel guard rails" (FSV, 2005a), the RVS 08.23.06 "Road equipment - Concrete guide walls" (FSV, 2005b), and the RVS 08.23.07 "Road equipment Traffic light signal systems" (FSV, 2009c), which provide recommendations for approval procedures. Furthermore, RVS 05.02.31 "Guiding equipment, restraint systems Requirements and erection" (FSV, 2007a) also provides recommendations for the structural design. RVS 08.10.04 "Bridge equipment - guidance devices" (FSV, 2009d) also provides approval guidance for vehicle restraint systems, but it is currently replaced by the "Standardised performance descriptions for traffic and infrastructure" (LB-VI) (FSV, 2018), which is issued by FSV, the Austrian Research Society Road - Rail - Transport, as is the case for all RSVs. A summary of applicable design standards may be found in the RVS 12.01.12 "Standards in the operational maintenance of national roads" (FSV, 2013a). Further design guidance for highways is provided in Austria by the "Planning Manual ASFINAG Road - Construction Technical Guideline" (Autobahnen- und SchnellstraßenFinanzierungs-Aktiengesellschaft [ASFINAG], 2015).

\section{Background research}

Advice on the design of roadside and restraint structures for motorways has also been developed through large scale research projects. In Weninger-Vycudil et al. (2009), the introduction of maintenance backlogs is used to assess the condition of various road infrastructure components such as pavements, engineering structures (e.g. bridges, tunnels, walls), and road furniture. To that end a series of interviews with owners is conducted, and the collected data are used for improved condition and performance indicators and the associated development of inspection and maintenance strategies.

The outcomes of the ERA NET European project "Holistic Evaluation of Road Assessment" (HEROAD) are presented in Sjögren et al. (2013). This document focuses on current practices for the assessment of road assets in Europe, based on interviews, literature reviews and the participants' experience. The case studies included in this report address, among other things, measurement methods for pavement fretting, ruts, and grip (skid resistance). Also, structures that need to withstand vehicle impact are characterized with regards to their maintenance importance by all investigated road shareholder groups as highimportance (by road users and operators), or as medium importance (by neighboring third-parties, e.g. owners and operators of adjacent rail, utilities, built assets, land).

A critical presentation of monitoring techniques is provided in Spielhofer (2014) with focus on the performance assessment of various road components through manual inspections, fixed safety cameras, satellites, and mapping vehicles. "Roadstar" is one of the mapping vehicles developed and used in Austria. The various items considered for monitoring include components sensitive to vehicle lane departure and impact, i.e. signs and markings, masts and poles, hydrants. Federal Ministry of Transportation, Building and Urban Development (2011) and ERA-NET ROAD (2012) provide a description of the outcomes from the project "Asset Service Condition Assessment Methodology" (ASCAM), which also addresses the state-of-theart condition assessment of road equipment. They deal with currently implemented data collection monitoring methods, maintenance measures and acceptable end user service levels in various European countries and focus on the visibility and visual guidance of road markings, road studs, delineator posts, fixed signs, Variable Message Signs (VMS) and road lighting. The project outcomes indicate that condition assessment of road equipment is rare, mostly because of the lack of suitable instruments.

The deliverables of the project "Practical Road Equipment Measurement, Understanding and Management" (PREMIUM) are presented in Benbow and Wright (2017), Spielhofer et al. (2016), Spielhofer, Osichenko, Leal, Benbow, and Wright (2017a, 2017b). This project looked at road markings, road signs, vehicle restraint systems and noise barriers, with the aim to identify each asset's key characteristics, the appropriate monitoring techniques and data interpretation, and the associated management strat- 
egies based on surveys. Of the components mentioned above, road signs (Spielhofer et al., 2017b) and more pronouncedly noise barriers (Spielhofer et al., 2016) and restraint systems (Spielhofer et al., 2017a) have also been assessed with respect to their structural response in vehicle impact and structural loss situations, and some quantitative target requirements for the structural response of these systems can be derived.

A risk-based asset management approach is presented in Spielhofer et al. (2015). This approach addresses road infrastructure in a comprehensive manner, with an emphasis on civil engineering structures (pavement, structures including bridges and retaining walls, tunnels, road furniture, drainage and geotechnical assets). In this project, a spreadsheet-based risk management tool is developed, and a realistic case study is presented. The various structures are categorised based on their vulnerability and consequence of loss, while the asset specific risks are then aggregated for the road system. This study also allows for a quantifiable performance level of the assets in consideration.

The volume of articles presented by Troutbeck (2013) provides international paradigms for the design and assessment of roadside structures, best practice case studies with focus on the minimisation of fatal and serious injuries from vehicle impacts, and recent advances in the technology of roadside structures. As such, it provides a thorough overview of the impact values accepted in correlation with the road design speed, vehicles' types, road geometry layout and further road engineering parameters.

Driver behaviour, as a unit, or in a driving culture context, could influence the above statistical expectations. Since road operators have minimal control over these effects, and since these effects can be considered as uniformly spread across the network, they are not accounted for in the maintenance and mitigation prioritisation process. The same consideration applies for environmental conditions.

\section{Likelihood of events in transport networks}

\subsection{Assessment approach}

The probability of an impact of a vehicle on a road furniture $p_{S \text { simpact }}$ can be determined in accordance with Eqn (1), which is newly introduced herein together with Eqns (2)-(16). In consequence, a risk property can be derived from this likelihood of occurrence. In particular, Eqn (1), as shown in Table 1, can be broken down into the following three main terms:

a) The accepted probability of occurrence of an impact or the accepted probability of failure of a noncompliant traffic flow (for example, accidents) for

Table 1. Descriptive quantities for computing the vehicle impact probability according to Eqn (1)

\begin{tabular}{|c|c|c|c|}
\hline Symbol & Specification & Unit & Value \\
\hline$p_{S, \text { impact }}$ & vehicle impact probability according to Eqn (1) & {$[-]$} & $0-1$ \\
\hline$p_{f, N O R M}$ & standard specific safety standards associated with a vehicle impact probability & {$[-]$} & $1 \cdot 10^{-6}$ \\
\hline$\eta_{F, L N}$ & increasing factor for the impact force - due to the longitudinal inclination of the lane & {$[-]$} & \\
\hline$\eta_{F, Q N}$ & due to the transverse inclination of the lane & {$[-]$} & \\
\hline$\eta_{F, K r}$ & due to curvature of the lane & {$[-]$} & \\
\hline$f_{G}$ & fragility associated with the lane grip & {$[-]$} & $0-1$ \\
\hline$p_{f, G, N O R M}$ & standard specific vehicle impact probability & {$[-]$} & $1 \cdot 10^{-6}$ \\
\hline$p_{f, G, L I M I T}$ & upper threshold of the vehicle impact probability e.g $p_{f}=2 \cdot 10^{-6}$ & {$[-]$} & $2 \cdot 10^{-6}$ \\
\hline$f_{L}$ & fragility associated with the lane longitudinal inclination & {$[-]$} & $0-1$ \\
\hline$p_{f, L, N O R M}$ & standard specific vehicle impact probability & {$[-]$} & $1 \cdot 10^{-6}$ \\
\hline$p_{f, L, L I M I T}$ & upper threshold of the vehicle impact probability e.g $p_{f}=2 \cdot 10^{-6}$ & {$[-]$} & $2 \cdot 10^{-6}$ \\
\hline$f_{O}$ & fragility associated with the surface damages in the pavement & {$[-]$} & $0-1$ \\
\hline$p_{f, O, N O R M}$ & standard specific vehicle impact probability & {$[-]$} & $1 \cdot 10^{-6}$ \\
\hline$p_{f, O, L I M I T}$ & upper threshold of the vehicle impact probability e.g $p_{f}=2 \cdot 10^{-6}$ & {$[-]$} & $2 \cdot 10^{-6}$ \\
\hline$f_{R}$ & fragility associated with the surface cracks in the pavement & {$[-]$} & $0-1$ \\
\hline$p_{f, R, N O R M}$ & standard specific vehicle impact probability & {$[-]$} & $1 \cdot 10^{-6}$ \\
\hline$p_{f, R, L I M I T}$ & upper threshold of the vehicle impact probability e.g $p_{f}=2 \cdot 10^{-6}$ & {$[-]$} & $2 \cdot 10^{-6}$ \\
\hline$f_{S}$ & fragility associated with the ruts in the pavement & {$[-]$} & $0-1$ \\
\hline$p_{f, S, N O R M}$ & standard specific vehicle impact probability & {$[-]$} & $1 \cdot 10^{-6}$ \\
\hline$p_{f, S, L I M I T}$ & upper threshold of the vehicle impact probability e.g $p_{f}=2 \cdot 10^{-6}$ & {$[-]$} & $2 \cdot 10^{-6}$ \\
\hline$f_{V}$ & fragility associated with the traffic volume & {$[-]$} & $0-1.2$ \\
\hline$f_{G E}$ & fragility of the traffic velocity to the vehicle impact - fragility, see 4(a) & {$[-]$} & $0-1$ \\
\hline
\end{tabular}


standard-compliant routing elements of the road, $p_{f \text { NORM }}=1 \cdot 10^{-6}$; this value is assumed here as a matter of principle in current standards for civil engineering elements and associated technical systems.

b) Increasing the likelihood of an impact due to the layout of the road track, such as longitudinal inclination, transverse inclination, and curvature of the lanes. The corresponding increase factors $\eta_{F, L N}$, $\eta_{F, Q N}$ and $\eta_{F, K R}$ with respect to the longitudinal inclination of lanes (LN), the transverse inclination of lanes (QN), and curvature of the lanes (KR) are calculated on the basis of physical laws of driving dynamics.

c) Increasing the likelihood of an impact due to peculiarities in the pavement surface, such as the pavement grip $p_{f} G$, the longitudinal evenness $p_{f^{\prime} L}$, the pavement damages $p_{f, O}$, the pavement cracks $p_{f, R}$ the pavement ruts $p_{f i S R}$, the traffic volume $p_{f} V$, and the vehicle velocity $p_{f, G E}$. The influence of the fragilities $\left(f_{G}, f_{L}, f_{O}, f_{R}, f_{S}\right)$ is based on the recorded data of the mapping vehicle "Roadstar", the fragility $f_{V}$ is based on actual counts by the road operators, while all are based on fragility related transfer functions ranging between 0 and 1 as described in more detail in the following paragraphs.

In Table 1 and Figure 1 more details of the individual parameters and the structure of the basic equation of the assessment concept are illustrated. These equations and parameters, which have been implemented in a use-oriented EXCEL spreadsheet shell, enable the computation and documentation of the probability of an impact of a vehicle on a road furniture $p_{\text {S,impact }}$ along the sections of a traffic line.

$$
\begin{aligned}
& p_{S, \text { impact }}=p_{f, N O R M}+\left(\eta_{F, L N}+\eta_{F, Q N}+\eta_{F, K R}\right) /{ }_{\ldots}
\end{aligned}
$$

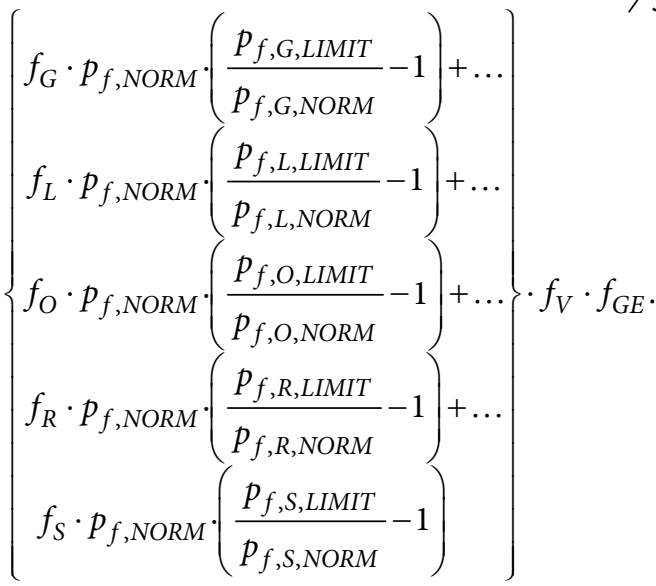

The respective impact risk assessment of the road furniture damage scenario, also implemented in the EXCEL shell is based on the risk assessment index $R_{i}$ which is calculated as follows:

$$
R_{i}=1+4 \cdot \frac{\left[p_{S, \text { impact }}-p_{f, N O R M}\right]}{p_{f, N O R M}} .
$$

In this context, consequence of an impact is associated with loss of a single entity and, as such, the risk in this study is arithmetically equal to the likelihood of the impact event.

\subsection{Force increasing or decreasing factors associated with the vehicle impact}

The increase of the impact force due to the longitudinal inclination of the lane can be determined from Eqn (3) taking into account the vertical force of gravity and the longitudinal inclination of the road for a running vehicle. Details about the individual parameters and the corresponding descriptive quantities can be found in Table 2.

$\eta_{F, L N, \text { max }}=1+\left\{V M^{\star} 9.81^{\star} \operatorname{SIN}\left(F_{L N}\right) /\left(v_{\text {max }}-v_{\text {min }}\right) \cdot V M\right\}$.

Respectively, the influence of the lane transverse inclination on the impact force can be determined from Eqn (4). For details see also Table 2.

$\eta_{F, Q N, \text { max }}=1+\left\{V M^{\star} 9.81^{\star} \operatorname{SIN}\left(F_{Q N}\right) /\left(v_{\text {max }}-v_{\text {min }}\right) \cdot V M\right\}$.

The increase of the impact force due to the radial, centrifugal force caused by the course of the vehicle in a curve can be determined from Eqn (5), which accounts for the influence of the radial force and the vertical gravity force. Details about the individual parameters and the corresponding descriptive quantities can be found in Tables 2 and 3.

$\eta_{F, K R, \text { max }}=1+\left\{V M \cdot \frac{v_{\text {max }}^{2}}{R} /\left[\left(v_{\text {max }}-v_{\text {min }}\right) \cdot V M\right] \cdot \sin \left(R_{\text {min }}\right)\right\}$.

\section{Fragility functions of vehicle impacts in traffic networks}

The geometric and condition data of the roadway collected, for example, by means of the data recorded with the "Roadstar" vehicle, serve as the basis for the determination of the $p_{\text {S.impct }}$ by use of various fragility curves and in accordance with Eqns (3) to (5). The maximum fragility of the vehicle impact probability vs. the lane longitudinal and transverse inclinations, and the lane curvature have been implemented in the EXCEL tool by a closed analytical procedure as described in 3.2. Furthermore, these fragility functions were formulated based on the following considerations, which are reported here for completeness:

(a) Equation (6) presents the functional relationship between the lane longitudinal inclination measured by the mapping vehicle and the force increasing factor (fragility). The exponent of Eqn (6) is chosen with $a=$ 3.0 in order to obtain a force increase factor of $n_{f, L N}=$ 1.0 for zero longitudinal inclination, and a value of $\eta_{F, L N \text { max }}$ as calculated in 2.2 for the maximum angle (see also Figure 3(a)). 


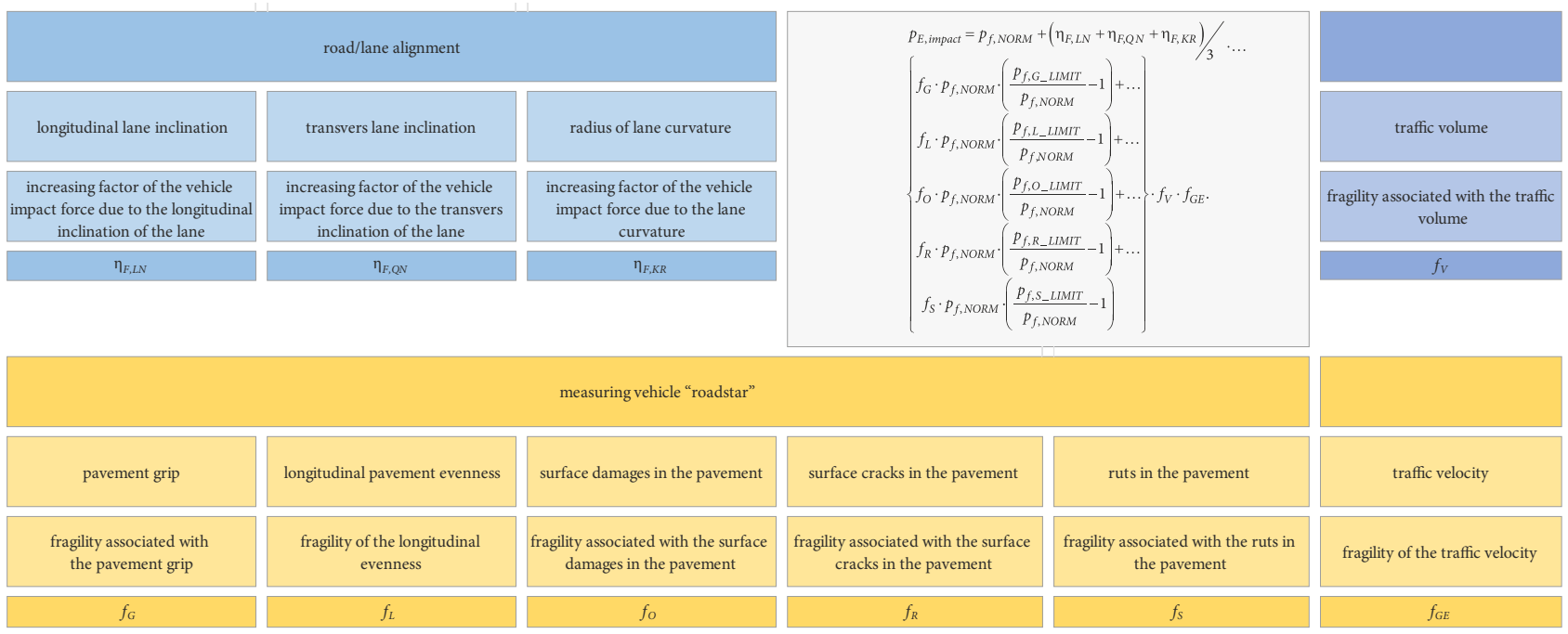

Figure 1. Vehicle impact probability according to Eqn (1) and its descriptive parameters

Table 2. Increase of the vehicle impact force according to the Eqns (3) to (5) due to the longitudinal lane inclination, the transverse lane inclination, the curvature of the lane

\begin{tabular}{|c|c|c|c|}
\hline Symbol & Specification & Unit & Eqn \\
\hline$\eta_{F, L N, \max }$ & max. increasing factor of the vehicle impact force - due to the longitudinal inclination of the lane & {$[-]$} & \multirow{2}{*}{ (3) } \\
\hline$F_{L N}$ & longitudinal inclination of the lane & {$\left[{ }^{\circ}\right]$} & \\
\hline$\eta_{F, Q N, \max }$ & max. increasing factor of the vehicle impact force - due to the transverse inclination of the lane & {$[-]$} & \multirow{2}{*}{ (4) } \\
\hline$F_{Q N}$ & transverse inclination of the lane & {$\left[{ }^{\circ}\right]$} & \\
\hline$\eta_{F, K R, \max }$ & max. increasing factor of the vehicle impact force - due to the lane curvature & {$[-]$} & \multirow{2}{*}{ (5) } \\
\hline$R$ & radius of the lane curvature & {$[\mathrm{m}]$} & \\
\hline$R_{\min }$ & minimum radius of the lane curvature & {$[\mathrm{m}]$} & \\
\hline$V M$ & mass of the considered vehicle & {$[\mathrm{kg}]$} & \\
\hline$v_{\max }$ & design velocity & {$[\mathrm{m} / \mathrm{sec}]$} & \\
\hline$v_{\min }$ & minimum vehicle speed at impact after braking & {$[\mathrm{m} / \mathrm{sec}]$} & \\
\hline
\end{tabular}

Table 3. Descriptive quantities for the functional relationship between the lane properties measured by the measuring vehicle and the increasing factor of the vehicle impact force

\begin{tabular}{|c|c|c|c|}
\hline Symbol & Specification & Unit & Eqn \\
\hline$\eta_{F, L N}$ & increasing factor of the vehicle impact force - due to the longitudinal inclination of the lane & {$[-]$} & \multirow{6}{*}{ (6) } \\
\hline$L N_{\min }$ & minimum longitudinal inclination, see $3(\mathrm{a})$ & {$\left[{ }^{\circ}\right]$} & \\
\hline$L N_{\max }$ & maximum longitudinal inclination, see 3(a) & {$\left[{ }^{\circ}\right]$} & \\
\hline 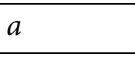 & exponent of Eqn (6) with $a=3.0$ gives a fragility $=1.0$ for a longitudinal inclination $=0^{\circ}$ & {$[-]$} & \\
\hline$L N$ & measured longitudinal inclination & {$\left[{ }^{\circ}\right]$} & \\
\hline$\eta_{F, L N}$ & fragility of the longitudinal inclination to the vehicle impact - fragility see 3(a) & {$[-]$} & \\
\hline$Q N_{\min }$ & minimum transverse inclination, see $3(\mathrm{~b})$ & {$\left[{ }^{\circ}\right]$} & \multirow{5}{*}{ (7) } \\
\hline$Q N_{\max }$ & maximum transverse inclination, see $3(\mathrm{~b})$ & {$\left[{ }^{\circ}\right]$} & \\
\hline$a$ & exponent of Eqn (7) with $a=2.2$ gives a fragility $=1.0$ for a transverse inclination $=0^{\circ}$ & {$[-]$} & \\
\hline QN & measured transverse inclination & {$\left[{ }^{\circ}\right]$} & \\
\hline$\eta_{F, Q N}$ & fragility of the transverse inclination to the vehicle impact - fragility see 3(b) & {$[-]$} & \\
\hline$K R_{\min }$ & minimum radius of lane curvature, see $3(\mathrm{c})$ & {$[\mathrm{m}]$} & \multirow{5}{*}{$(8)$} \\
\hline$K R_{\max }$ & maximum radius of lane curvature, see $3(\mathrm{c})$ & {$[\mathrm{m}]$} & \\
\hline 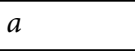 & exponent of Eqn (8) with $a=2.2$ gives a fragility $=1.0$ for a lane curvature radius $=6000 \mathrm{~m}$ & {$[-]$} & \\
\hline$K R$ & Measured radius of lane curvature & {$[\mathrm{m}]$} & \\
\hline$\eta_{F, K R}$ & fragility of the lane curvature to the vehicle impact - fragility, see 3(c) & {$[-]$} & \\
\hline
\end{tabular}


$\eta_{F, L N}=\left[1-\left(L N-L N_{\min }\right) /\left(L N_{\max }-L N_{\min }\right)^{a}\right] \cdot \eta_{F, L N \max }$

(b) Equation (7) subsequently presents the relationship between the lane transverse inclination measured by the mapping vehicle and the force increasing factor. This is graphically represented in Figure 3(b). The exponent of Eqn (7) is chosen with $a=2.2$ in order to obtain a force increase factor of $n_{f, Q N}=1.0$ for zero inclination, and $\eta_{F, Q N \max }$ as defined in 3.2 for the maximum possible inclination.

$\eta_{F, Q N}=\left[1-\left(Q N-Q N_{\min }\right) /\left(Q N_{\max }-Q N_{\min }\right)^{a}\right] \cdot \eta_{F, Q N \max }$.

(c) Equation (8) describes the influence of the mean lane curvature, as illustrated in Figure 3(c). The exponent of Eqn (8) is set to $a=2.2$ in order to obtain a force increase factor of $n_{f, K R}=1.0$ for a lane curvature $=$ $6000 \mathrm{~m}$ and $\eta_{F, \text { KRmax }}$ as per Eqn (5) for the minimum allowable curvature $=250 \mathrm{~m}$.

$\eta_{F, K R}=\left[1-\left(K R-K R_{\text {min }}\right) /\left(K R_{\text {max }}-K R_{\text {min }}\right)^{a}\right] \cdot \eta_{F, K R \max }$.

In addition to the influences discussed above, which can be handled in closed-form, unambiguously determinable fragility functions, there are properties in the traffic network which cannot be determined and integrated in such a straightforward manner. These may contain large uncertainties and they cannot be characterised and converted to fragility functions through a physical or mathematical approach. The associated types of fragility functions can be defined based on expert knowledge and performance thresholds, which can change and be adapted over time. This category of fragility curves is formulated in Eqns (9) to (15) below. Their parameters were adjusted in the course of this study based on the experience and expertise of infrastructure operators as described below.

Experts in this study are regarded professionals with management and technical lead roles in infrastructure asset technical evaluation and maintenance within the owners' organisation. Correspondingly, the judgement elicitation involved at least one substantive and one normative expert focusing on the occurrence anticipation and the quantification part respectively. The implication of different expert characteristics aims in parallel to reduce bias in the estimation outcomes. Moreover, since the experts in this case are recruited from the very same organisation and work collectively, the evaluation framework is in line with the Delphi method requirements, which accommodates reliable derivations. The main concepts for the implementation of expert opinions are drawn from Meyer and Booker (2001) and Linstone and Turoff (1975). The experts in the specific study are drawn from the Austrian Motorway Operator (ASFINAG) and they include field inspectors, engineers, and the senior management of the management departments. As a minimum, they carry 10 years of professional experience in inspections and asset management, and they have completed the national training program for the inspection of structures.

(a) Equation (9) defines the functional relationship between the heavy vehicle traffic volume and the probability of a vehicle impact, as seen in Figure 3(d). The exponent of Eqn (10) is chosen with $a=1.3$ in order to obtain a probability of a vehicle impact of $f_{V}=1.0$ for a JDTLV $=5300$, and further remain in accordance with the experts' judgement and the operator's statistical observations. The respective values for standard vehicle traffic volumes are $a=2.4$ and $\operatorname{JDTV}\left(f_{V}=\right.$ 1.0) $=40500$ (see also Eqn (9) and Figure 3(e)). $f_{V}=\left[1-\left(J D T L V_{\max }-J D T L V\right) /\right.$

$\left.\left(J D T L V_{\text {max }}-J D T L V_{\text {min }}\right)^{a}\right] \cdot \eta_{F, J D T L V}$;

$f_{V}=\left[1-\left(J D T V_{\max }-J D T V\right) /\right.$

$\left.\left(J D T V_{\text {max }}-J D T V_{\text {min }}\right)^{a}\right] \cdot \eta_{F, J D T V}$

(b) Equation (11) presents the functional relationship between the traffic speed and the probability of a vehicle impact. The exponent of Eqn (11) is chosen with $a=$ 3.0 in order to obtain a probability of a vehicle impact of $f_{G E}=1.0$ for a $v_{\text {max, heavy vehicle }}=80 \mathrm{~km} / \mathrm{h}$ or a $v_{\text {max.standard vehicle }}=130 \mathrm{~km} / \mathrm{h}$ (see also Figure $3(\mathrm{a})$ ).

$f_{G E}=\left[\left(D M-D M_{\text {min }}\right) /\left(D M_{\text {max }}-D M_{\text {min }}\right)^{a}\right]$.

(c) Equation (12) presents the functional relationship between the pavement grip and the probability of a vehicle impact. As seen in Figure 3(b), the exponent of Eqn (12) is chosen with $a=3.0$ in order to derive a probability of a vehicle impact of $f_{G}=1.0$ for the minimum grip conditions $G R_{\min }=5$, and a $f_{G}=0.4$ for a $G R=4$.

$f_{G}=\left[\left(G R-G R_{\text {min }}\right) /\left(G R_{\text {max }}-G R_{\text {min }}\right)^{a}\right]$.

(d) Equation (13) presents the functional relationship between the longitudinal evenness of the pavement and the probability of a vehicle impact. As seen in Figure 3(c), the exponent of Eqn (13) is adjusted to $a=7.0$ in order to derive a probability of a vehicle impact of $f_{L}=1.0$ for the worst case evenness conditions $L E_{\min }=5$, and a $f_{L}=0.1$ for a $L E=4$. This captures the particularly steep increase of accidents expected due to an uneven (bumpy) road pavement.

$f_{L}=\left[\left(L E-L E_{\text {min }}\right) /\left(L E_{\text {max }}-L E_{\text {min }}\right)^{a}\right]$.

(e) Equation (14) presents the functional relationship between the surface damages of the pavement and the probability of a vehicle impact. As seen in Figure 3(d), the exponent of Eqn (14) is chosen with $a=3.0$ in order to obtain a probability of a vehi- 
cle impact of $f_{O}=1.0$ for the most adverse level of damage $O S_{\min }=5$, and a $f_{O}=0.4$ for a $O S=4$.

$f_{O}=\left[\left(O S-O S_{\min }\right) /\left(O S_{\max }-O S_{\min }\right)^{a}\right]$.

(f) Similarly, Eqn (15) relates the pavement surface cracking with the probability of a vehicle impact. The exponent of Eqn (15) is chosen with $a=3.0$ in order to obtain an impact probability of $f_{R}=1.0$ for the most adverse cracking level $R I_{\min }=5$, and a $f_{R}=0.4$ for a $R I=4$.

$f_{R}=\left[\left(R I-R I_{\min }\right) /\left(R I_{\max }-R I_{\min }\right)^{a}\right]$.

(g) As with the above pavement damage factors, Eqn (16) addresses the pavement ruts to the vehicle impact probability. The exponent of Eqn (16) is $a=3.0$ in order to obtain an impact probability of $f_{S}=1.0$ for the deepest ruts observed or temporarily allowed, denoted as $S R_{\min }=5$, and a $f_{S}=0.4$ for a $S R=4$.

$f_{S}=\left[\left(S R-S R_{\min }\right) /\left(S R_{\max }-S R_{\min }\right)^{a}\right]$.

\section{Risk assessment vs. damage classes}

The assessment of the vehicle impact on a traffic facility can be performed based on the newly introduced concept of the rating index $R_{i}$, which is derived with the aid of Eqn (1). With the evaluation index $R_{i}$, the following probability assessment of a vehicle impact can be characterised:

$-1.0 \leq R_{i} \leq 2.5$ : the road geometry, the pavement surface characteristics and the driving dynamics factors (traffic strength and speeds) have negligible or no effects on the impact risk.

$-2.6 \leq R_{i} \leq 4.0$ : the road geometry, the pavement surface characteristics and the driving dynamics factors have negligible effects on the impact risk.

- $4.1 \leq R_{i} \leq 5.5$ : the road geometry, the pavement surface characteristics and the driving dynamics factors have a medium to large effects on the impact risk.

$-R_{i}>$ 5.6: the road geometry, the pavement surface characteristics and the driving dynamics factors have significant effects on the impact risk.

The rating index $R_{i}$ concept is based on the assumption of an impact occurrence probability of $p_{f, N O R M}=1 \cdot 10^{-6}$ $\left(R_{i}=1.0\right)$ for a lane alignment (a) without a longitudinal inclination (b) without a transverse inclination, (c) with a very large radius of curvature, (d) with an optimal road surface condition, (e) with a predefined amount of traffic per design (JDTV or JDTLV), and (f) a predefined design velocity.

Deviations from the above defined standards leads, based on Eqn (1), to an occurrence probability $p_{S \text { simpact }}$ larger than $p_{f \text { NORM }}$, see Figure 1 . In addition, for the determination of $p_{\text {Simpact }}$ for each route section or element ID the following points need to be differentiated:

- a traffic flow in the main lane (HFS);

- a traffic flow in the secondary/side lanes (NFS);
- a traffic flow in the direction of the road kilometre;

- a traffic flow of the road kilometre in the opposite direction.

For instance, Figure 2 shows the evaluation results summarized in one sheet (risk factor columns BL to BN) of one main motor highway in Austria. This assessment was done for the main lane (HFS) and the Annual Average Daily Traffic volume of truck-like vehicles JDTLV.

\section{Evaluation and decision-making procedures}

As discussed above, the proposed model has been calibrated and applied on real data from the Austrian motorway network, while experts of the motorway operator have informed the evaluation and decision-making procedures. The evaluation is based on reliability assessment, which is then also expressed in terms of fragility curves, and definitions of the main terms are given in the introduction. The evaluation tool first distinguishes traffic flow in the different lanes, i.e. in the main lane (HFS) and the secondary/ side lanes (NFS). The data group is further broken down with respect to the vehicle type composition, i.e. the heavy goods/truck like vehicle proportion and standard traffic (JDTV and JDTLV respectively). It then calibrates the reliability score against the optimum conditions meaning no damage of the road surface and ideal alignment, and the associated failure threshold or target failure probability, where failure is the vehicle departure from its lane. The alignment benchmarks mentioned above correspond to a reliability index of $\beta=4.7$ and failure probability of $p_{f}=$ $10^{-6}$ per annum, as a commonly accepted threshold value for technical and infrastructure elements in the realm of civil engineering. This reliability score is then reduced with certain changes in the road alignment, velocity, and condition, these forming the input data to the decision model. The effects of non-ideal road alignment are calculated based on fundamental physics principles of kinetics and kinematics; curvature or an adverse transverse and longitudinal inclination of the road section leads to a reduction of the reliability present in the system $\left(\beta_{\text {reduced }}\right)$ and thus a higher probability hence risk of a vehicle's departure from its lane. There may also be a positive effect of non-straight alignment, which leads to increased safety under circumstances, as seen in Figures 3(a) and 3(b). The effects of road surface damage or generally low quality are assigned a ranking, based on expert judgement and a 5-point rating system, and it is reduced from the optimum conditions (score $=1$ and $\beta=4.7$ ) to a marginally acceptable road condition (score $=5$ and $\beta=\beta_{\text {acceptable }}$ ). The reliability decrease from the optimum conditions $\Delta \beta_{i}$ for each score ( $i=1$ to 5$)$ is calculated through Eqn (17):

$$
\Delta \beta_{i}=\frac{4.7-\beta_{\text {acceptable }}}{5} .
$$

The effect of travel speed is also processed with the rating system described above, but it is factored also against quantitative criteria, i.e. the speed limit. 


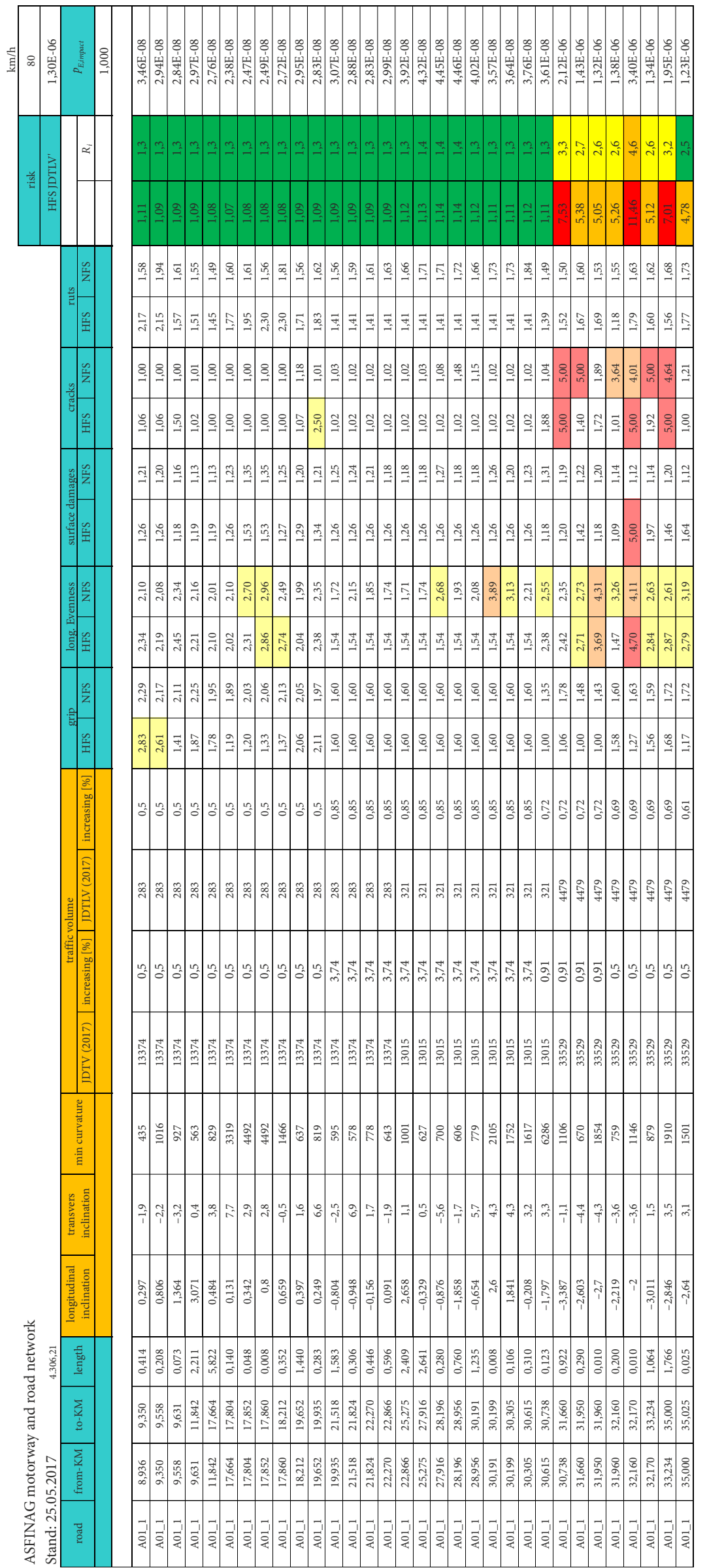

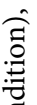

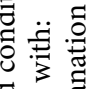
范

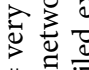
in in

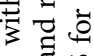
요요 $=3$.

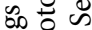

$\Xi \Xi \approx$

馬

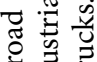

永焉 후

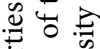

ปิ

을 들

范

రే

덴히

윤

记

ङ

寻名寻

总是

可

च्ञ त्ञ

है

它

응 प्षै:

氙

要

ธี

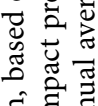

ธิ ڤ્छ

总卷

$\pm$

过

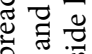

के जक

胥藏至

z

롱

प눙 졍

늘 잉

过

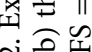

i已至

苛 


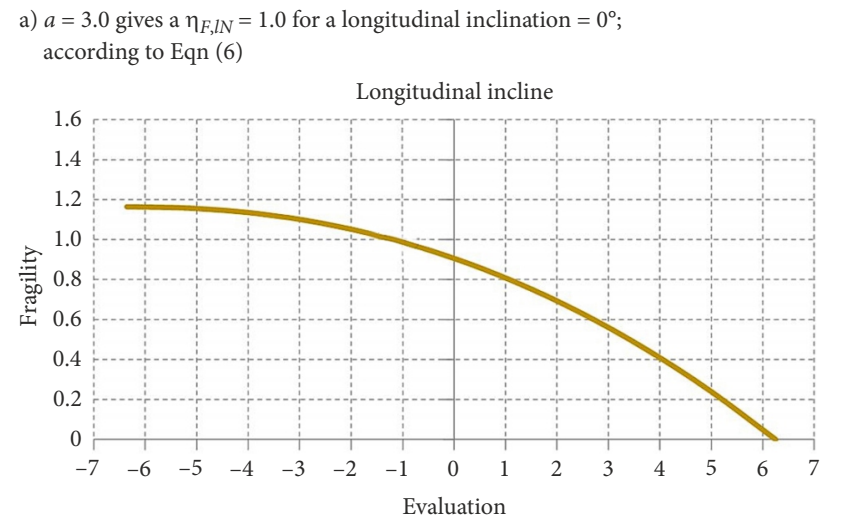

c) $a=2.2$ gives a $\eta_{F, K R}=1.0$ for a curvature radius $=6000 \mathrm{~m}$;
according to Eqn $(8)$
d) $a=2.2$ gives a $f_{V}=1.0$ for a JDTLV $=5300$; according to Eqn (9)

b) $a=2.2$ gives a $\eta_{F, Q N}=1.0$ for a transverse inclination $=0^{\circ}$;
according to Eqn $(7)$

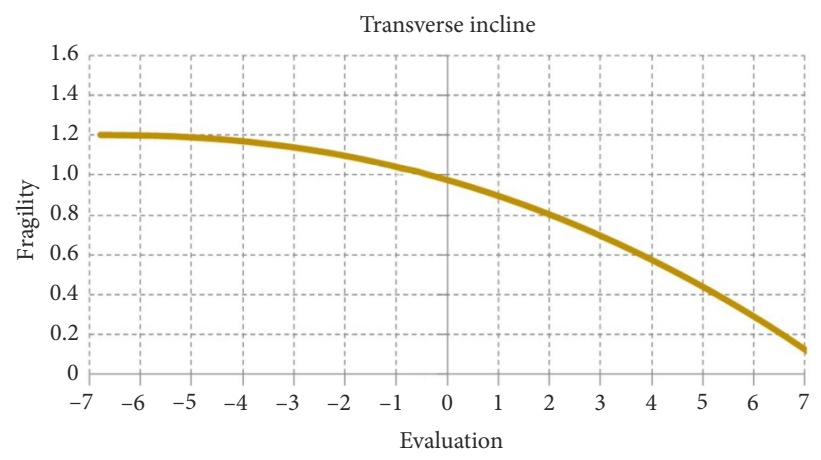
e) $a=3.0$ gives a $f_{V}=1.0$ for a JDTV $=40500$; according to Eqn (10)
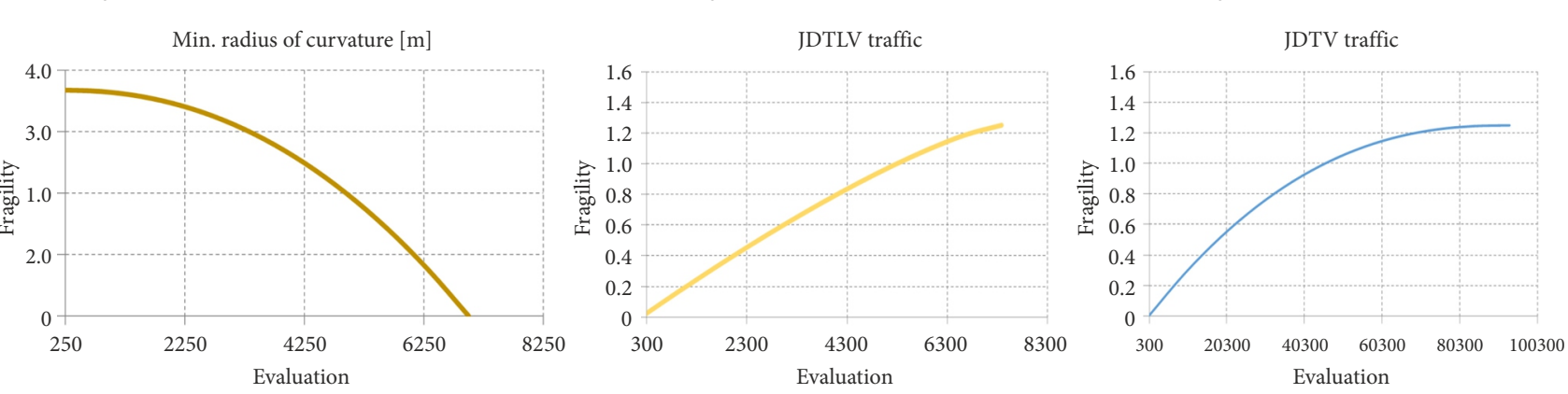

Figure 3. Increasing factor of the vehicle impact force due to: (a) the longitudinal inclination of the lane, (b) the transvers inclination of the lane, and (c) the curvature of the lane, (d) JDTLV = annual average traffic density for trucks and (e) JDTV = annual average traffic density for cars

Figure 2 shows in excerpts the scores of the risk assessment index $R_{i}$ calculated according to Eqn (1), broken down into main lane, secondary lane, passenger traffic and freight traffic in $\mathrm{km}$ and against $\mathrm{km}$ direction of travel, as well as the extreme values from these in the two right columns of the EXCEL overview sheet. The evaluation indices of the representation in Figure 4 are assigned to the in-situ concrete guide walls in the central stripe area by means of the distance- $\mathrm{km}$ data.

Table 4 presents those parameters, which the decision makers can adapt or parameterise in the course of its overall assessment of the network. In particular, the following can be considered as significant basic variables, which have to be defined in a first step for the definition of the desired safety level:

- $\beta_{\min }$ or $\beta_{\text {norm }}$ are the reliability limits for the rating group pavement grip, longitudinal evenness of the pavement, surface damages of the pavement, surface cracks in the pavement, ruts in the pavement. A $\beta_{\min }=4.7$ is an accepted maximum failure probability in pavement grip $p_{\text {frag,GR }}$.

- The accepted maximum failure probability (here assumed as $2.1 \cdot 10^{-6}$ ) which equals to the failure probability associated to the pavement grip $p_{\text {frag } G R}$, to the pavement evenness $p_{\text {frag } L E}$, to the surface damage $p_{\text {frag }} O S$, to the pavement cracks $p_{\text {frag } R I}$ and to the pavement ruts $p_{\text {frag } S R}$ (see also FSV, 2005b).

- The fragility parameters $a$, used for the description of the influence of grip, longitudinal evenness, surface damage, cracks, ruts on the residual failure probability $p_{r e s}$, which is estimated by means of fragility functions.

\section{Actual case studies on the Austrian motorway network and sensitivity analyses}

The implementation of the concept for the risk evaluation of existing road furniture due to vehicle impacts has been undertaken on the basis of real traffic situations, the actual alignment characteristics, and the current road surface conditions identified on the Austrian motorway network at the inception of this study (Table 5).

Figure 5(a) shows the evaluation indices for the risk of impact on the guide walls of the motorway network in Austria in relation to the JDTLV on the main lanes. The fluctuations and, in part, the clustering potential of the index result from the alignment characteristics, the road surface properties, and the traffic flows as well as vehicle speeds. Figure 5(b) shows these indexes in relation to JDTLV on the side lanes, Figure 5(c) to JDTV on the main lanes, Figure 5(d) to JDTV on the side lanes. The risk of an impact from the JDTV appears to be somewhat higher according to this model, due to the amount of traffic and speed. Based on the histograms associated with Figures 5(a) to 5(d), the JDTLV-specific graphs in Figures $5(\mathrm{e})$ and 10(f) show a sample accumulation in the ranking 
a) $a=2.2$ gives a $f_{G E}=1.0$ traffic velocity $=80 \mathrm{~km} / \mathrm{h}$ or $130 \mathrm{~km} / \mathrm{h}$

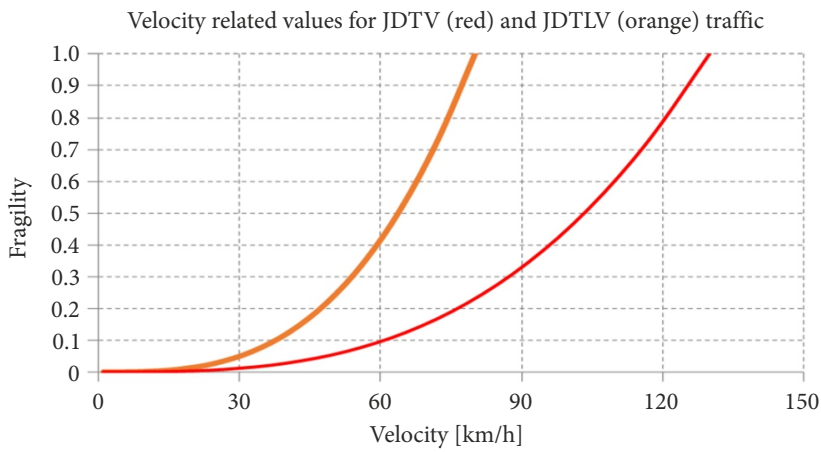

c) $a=7.0$ gives a $f_{L}=0.1$ for a evenness rating $=4$ and 0.01 for a rating $=3$; according to Eqn (13)

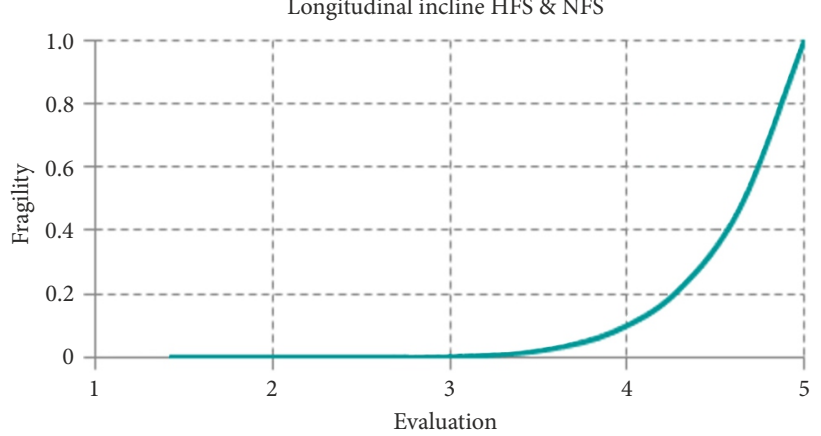

e) $a=2.2$ gives a $f_{R}=0.1$ for a damage rating $=5$ and 0.1 for a rating $=3$; according to Eqn (15)

Cracks HFS

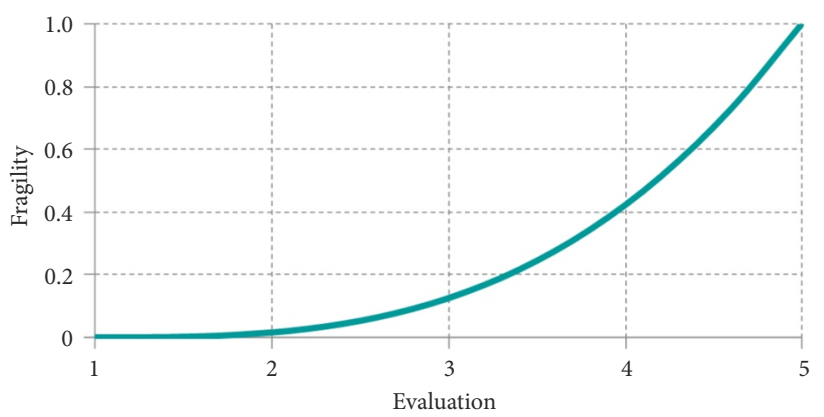

b) $a=2.2$ gives a $f_{G}=0.4$ for a grip rating $=4$ and 0.1 for a rating $=3$; according to Eqn (12)

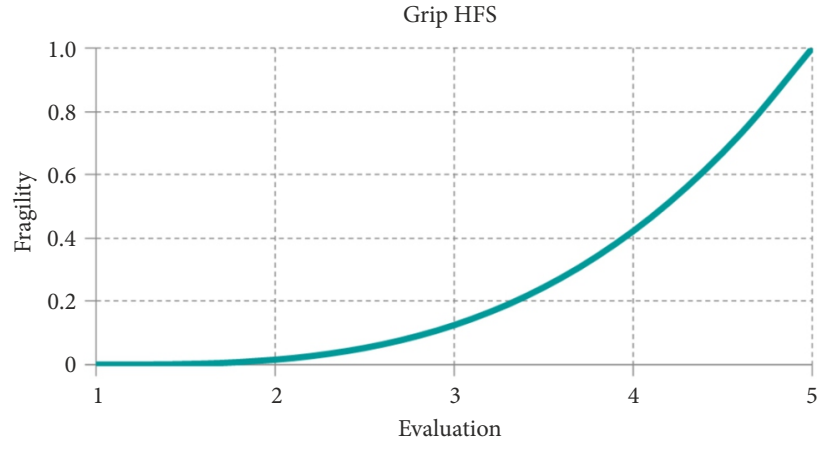

d) $a=2.2$ gives a $f_{O}=1.0$ for a damage rating $=5$ and 0.1 for a rating $=3$; according to Eqn (14)

Surface damage HFS \& NFS

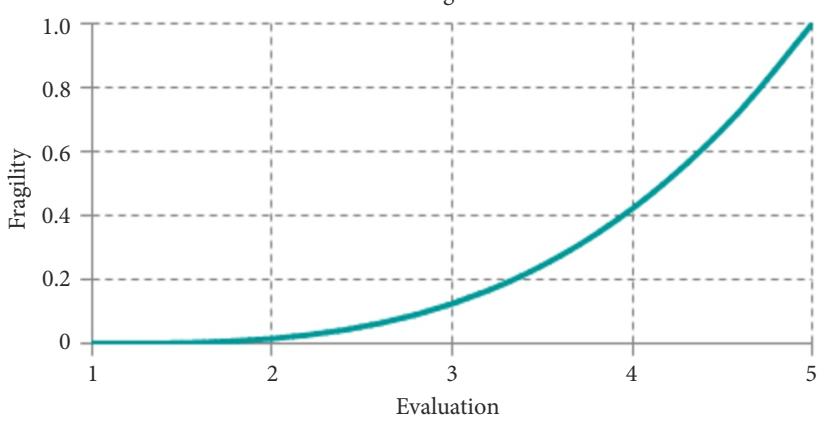

f) $a=2.2$ gives a $f_{R}=0.1$ for a ruts rating $=5$ and 0.1 for a rating $=3$; according to Eqn (16)

Ruts HFS

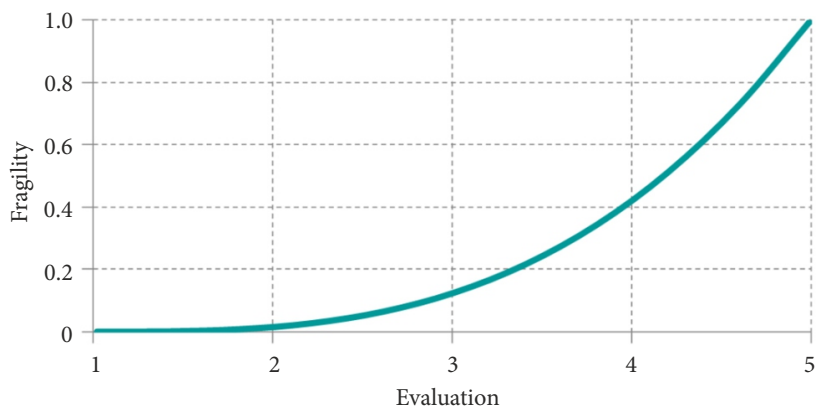

Figure 4. Fragility on the vehicle impact due to: (a) the traffic velocity, (b) the pavement grip, (c) the longitudinal pavement evenness, (d) the pavement damages, (e) the pavement cracks, and (f) the pavement ruts

regions of 1.5 and 2.5. This is described by the bi-modal distribution with respective peak concentrations. Also, a further concentration is evident at classes greater than 5 . The patterns are comparable in the main and side lanes. The JDTV-specific graphs in Figures 5(g) and 5(h) show a population accumulated in the region of class 2.5 and of 4.0. Again, a further concentration is evident in classes greater than 5; however, it is shown that there is a stronger accumulation generally at higher classes, compared to the JDTLV-specific graphs. The patterns are comparable in the main (HFS) and side (NFS) lanes. The graphs in Figures 5(a) to 5(d), allow for a visual understanding of high risk segments of the highways geographically, and a respective prioritisation by risk levels. On the basis of the histograms of Figures 5(e) to 5(h), the actual volumes of structures under risk are more evident. It is apparent that items in high risk levels $\left(R_{i}>5\right)$ are slightly more sensitive to main lane traffic. Simultaneously, low risk regions are denser for main lane traffic data. Risk also appears reduced in conjunction with heavy vehicle traffic, although combined traffic flows exhibit a more concentrated accumulation around risk rating $R_{i}=2.5$.

The influence of travel speed on the risk rating, for JDTV and JDTLV on the main and side lanes is shown in Figures 6(a) to 6(d). A shift in the class values from 2.5 to about 1.75 is disclosed, together with a smaller scatter around this range for a speed reduction of $20 \%$ - the classes greater than 5 occur only sporadically. Accordingly, a speed reduction measure can be implemented on the network in order to reduce the assets risk accordingly. This has been found to be an optimal solution between road network performance and risk of asset loss. 
Table 4. Descriptive quantities for the functional relationship between (a) the traffic volume, (b) traffic velocity, (c) pavement grip, (d) longitudinal evenness, (e) pavement damages, (f) the pavement cracks and the probability of the vehicle impact

\begin{tabular}{|c|c|c|c|}
\hline Symbol & Specification & Unit & Eqn \\
\hline$J D T V L_{\min }$ & minimal $J D T V L$, see $3(\mathrm{~d})$ & $\begin{array}{c}\text { [number of } \\
\text { vehicles] }\end{array}$ & \multirow{5}{*}{ (9) } \\
\hline$J D T V L_{\max }$ & maximal JDTVL, see $3(\mathrm{~d})$ & $\begin{array}{c}\text { [number of } \\
\text { vehicles] }\end{array}$ & \\
\hline$a$ & exponent of Eqn (9) with $a=2.2$ gives a fragility $=1.0$ for a $J D T V L=4300$ & {$[-]$} & \\
\hline$J D T V L$ & measured JDTVL & $\begin{array}{c}\text { [number of } \\
\text { vehicles] }\end{array}$ & \\
\hline$f_{V}$ & fragility of JDTVL to the vehicle impact - fragility, see $3(\mathrm{~d})$ & {$[-]$} & \\
\hline$D M_{\min }$ & minimal traffic velocity, see $4(a)$ & {$[\mathrm{m} / \mathrm{sec}]$} & \multirow{5}{*}{$(11)$} \\
\hline$D M_{\max }$ & maximal traffic velocity, see $4(\mathrm{a})$ & {$[\mathrm{m} / \mathrm{sec}]$} & \\
\hline$a$ & exponent of Eqn (11) with $a=2.2$ gives a fragility $=0.4$ for a traffic velocity $=60 \mathrm{~km} / \mathrm{h}$ & {$[-]$} & \\
\hline$D M$ & measured traffic velocity & {$[\mathrm{m} / \mathrm{sec}]$} & \\
\hline$f_{G E}$ & fragility of the traffic velocity to the vehicle impact - fragility, see 4(a) & {$[-]$} & \\
\hline$G R_{\min }$ & minimal pavement grip, see $4(\mathrm{~b})$ & {$[-]$} & \multirow{5}{*}{$(12)$} \\
\hline$G R_{\max }$ & maximal pavement grip, see $4(\mathrm{~b})$ & {$[-]$} & \\
\hline$a$ & exponent of Eqn (12) with $a=2.2$ gives a fragility $=0.4$ for a rating $=4$ and 0.1 for rating $=3$ & {$[-]$} & \\
\hline GR & recorded grip rating & {$[-]$} & \\
\hline$f_{G}$ & fragility of the pavement grip to the vehicle impact - fragility, see 4(b) & {$[-]$} & \\
\hline$L E_{\text {min }}$ & minimal longitudinal evenness, see $4(\mathrm{c})$ & {$\left[{ }^{\circ}\right]$} & \multirow{5}{*}{$(13)$} \\
\hline$L E_{\max }$ & maximal longitudinal evenness, see $4(\mathrm{c})$ & {$\left[{ }^{\circ}\right]$} & \\
\hline$a$ & exponent of Eqn (13) with $a=7.0$ gives a fragility $=0.4$ for a rating $=4$ and 0.1 for rating $=3$ & {$[-]$} & \\
\hline$L E$ & recorded longitudinal evenness rating & {$\left[{ }^{\circ}\right]$} & \\
\hline$f_{L}$ & fragility of the longitudinal evenness to the vehicle impact - fragility, see 4(c) & {$[-]$} & \\
\hline$O S_{\min }$ & minimal pavement surface damages, see $4(\mathrm{~d})$ & {$[-]$} & \multirow{5}{*}{$(14)$} \\
\hline$O S_{\max }$ & maximum pavement surface damages, see $4(\mathrm{~d})$ & {$[-]$} & \\
\hline 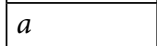 & exponent of Eqn (14) with $a=2.2$ gives a fragility $=0.1$ for a rating $=3$ & {$[-]$} & \\
\hline OS & recorded rating of the pavement surface damages & {$[-]$} & \\
\hline$f_{O}$ & fragility of the pavement surface damages to the vehicle impact - fragility, see $4(\mathrm{~d})$ & {$[-]$} & \\
\hline$R I_{\min }$ & minimal crack width in pavement, see 4(e) & {$[\mathrm{mm}]$} & \multirow{5}{*}{$(15)$} \\
\hline$R I_{\max }$ & maximum crack width in pavement see $4(\mathrm{e})$ & {$[\mathrm{mm}]$} & \\
\hline$a$ & exponent of Eqn (15) with $a=2.2$ gives a fragility $=0.4$ for a rating $=4$ & {$[-]$} & \\
\hline$R I$ & recorded crack widths of the pavement & {$[\mathrm{mm}]$} & \\
\hline$f_{R}$ & fragility of the crack widths of the pavement to the vehicle impact - fragility, see 4(e) & {$[-]$} & \\
\hline$S R_{\min }$ & minimal road ruts, see $4(\mathrm{f})$ & {$[\mathrm{mm}]$} & \\
\hline$S R_{\max }$ & maximum road ruts, see $4(\mathrm{f})$ & {$[\mathrm{mm}]$} & \\
\hline$a$ & exponent of Eqn (16) with $a=2.2$ gives a fragility $=0.1$ for a rating $=3$ & {$[-]$} & \\
\hline$S R$ & recorded rating of the road ruts & {$[\mathrm{mm}]$} & \\
\hline$f_{S}$ & fragility of the road ruts to the vehicle impact - fragility, see $4(\mathrm{f})$ & {$[-]$} & \\
\hline
\end{tabular}

Table 5. Input variables of the vehicle impact analysis

\begin{tabular}{|l|c|c|c|c|c|c|c|}
\hline & Fragility parameter, $a$ & Maximum & $p_{f_{-} \text {LIMIT }}$ & $p_{f_{-} \text {NORM }}$ & $\beta_{\text {min }}$ & $\beta_{\text {norm }}$ \\
\hline & HFS & NFS & & & & & \\
\hline Traffic velocity & \multicolumn{2}{|c|}{$\mathbf{3}$} & & & & & \\
\hline JDTLV & \multicolumn{2}{|c|}{$\mathbf{1 . 3}$} & \multirow{2}{*}{$\mathbf{2 . 4}$} & & & & \\
JDTV & $\mathbf{3}$ & $\mathbf{3}$ & & $2.1 \mathrm{E}-06$ & $1.3 \mathrm{E}-06$ & & \\
\hline Pavement grip & $\mathbf{7}$ & $\mathbf{7}$ & & $2.1 \mathrm{E}-06$ & $1.3 \mathrm{E}-06$ & $\mathbf{4 . 6}$ & \\
\hline Longitudinal evenness & $\mathbf{3}$ & $\mathbf{3}$ & & $2.1 \mathrm{E}-06$ & $1.3 \mathrm{E}-06$ & & \\
\hline Pavement damages & $\mathbf{3}$ & $\mathbf{3}$ & & $2.1 \mathrm{E}-06$ & $1.3 \mathrm{E}-06$ & & \\
\hline Pavement cracks & $\mathbf{3}$ & $\mathbf{3}$ & & $2.1 \mathrm{E}-06$ & $1.3 \mathrm{E}-06$ & & \\
\hline Pavement rots & & & & & \\
\hline
\end{tabular}


a)

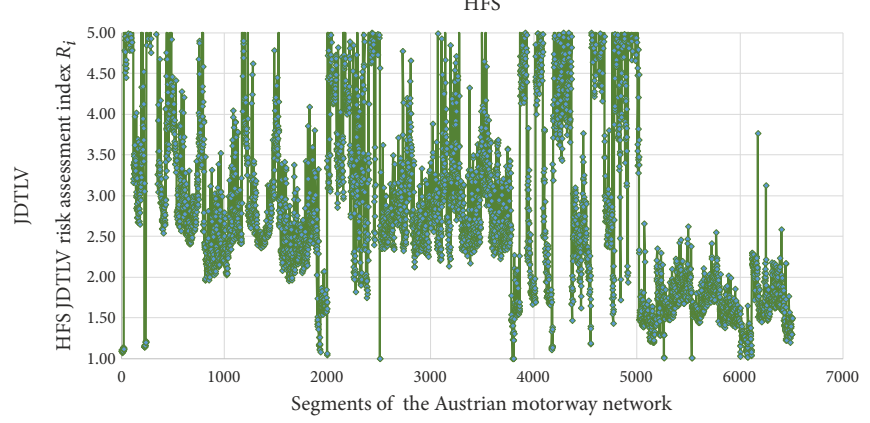

c)

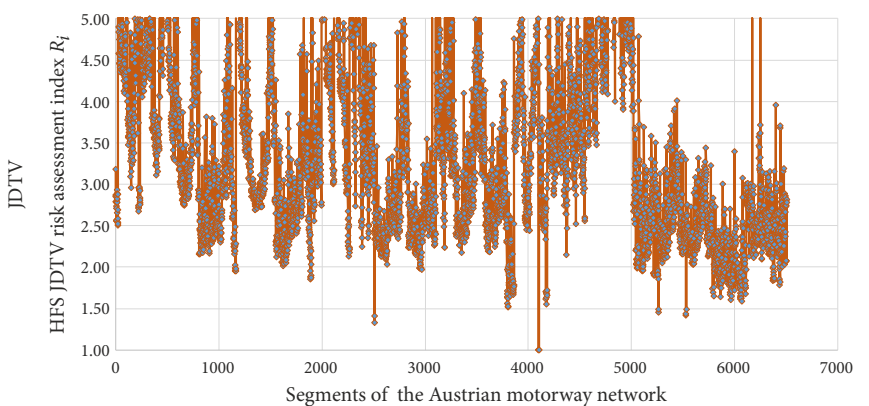

e)

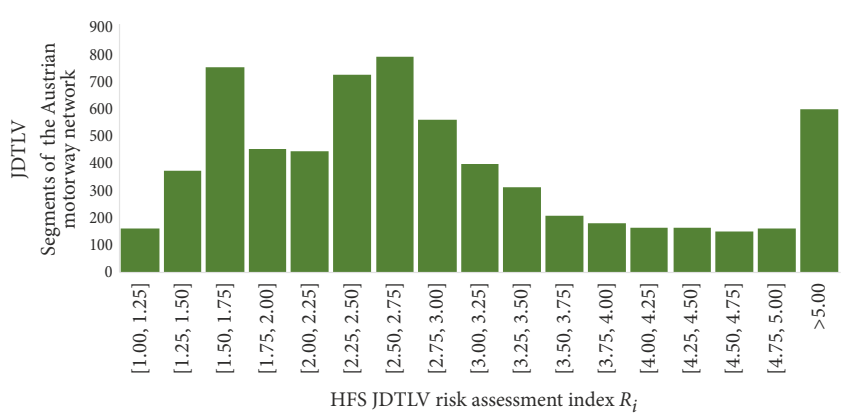

g)

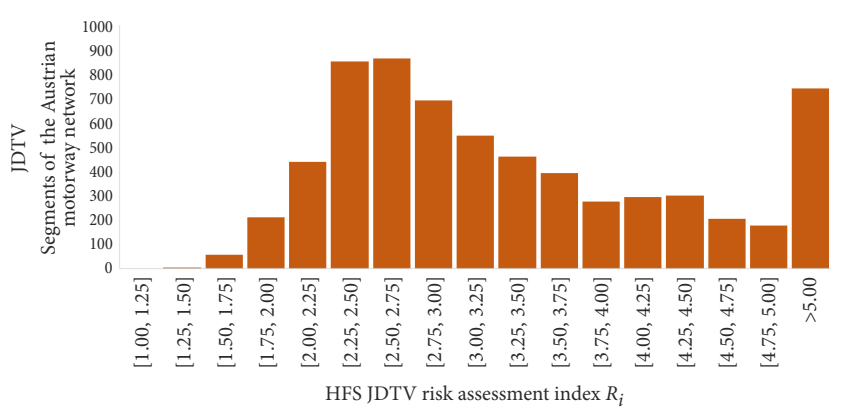

b)

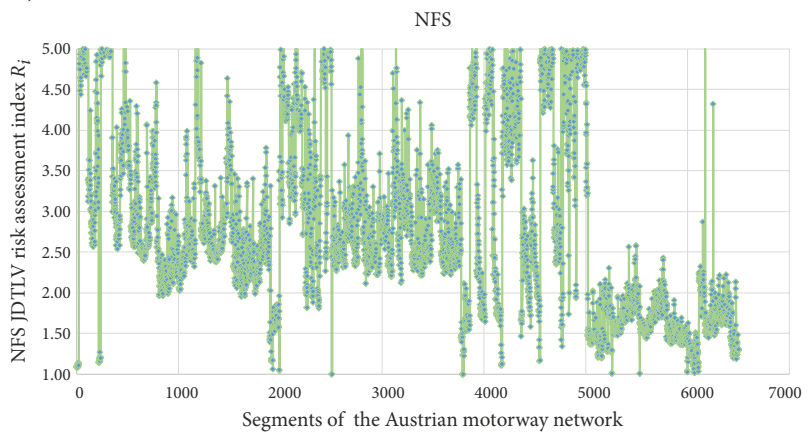

d)

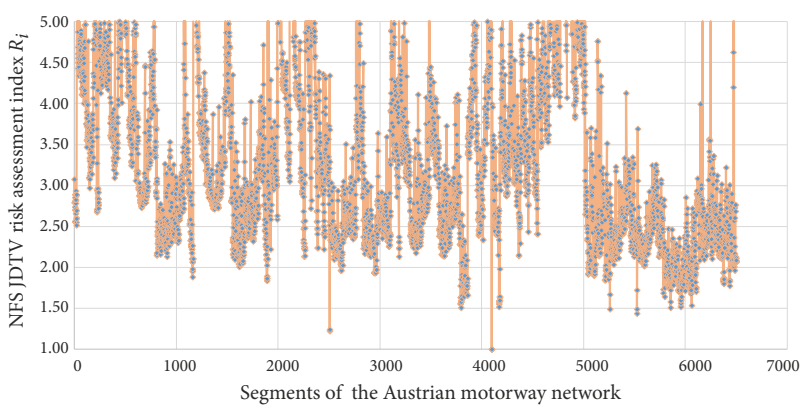

f)

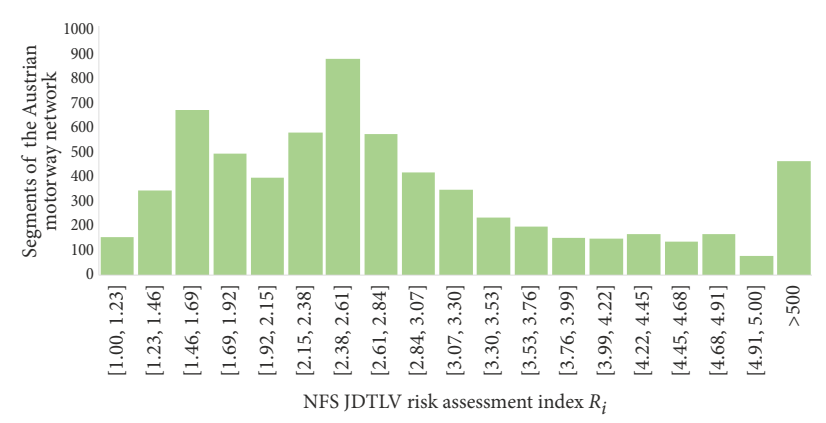

h)

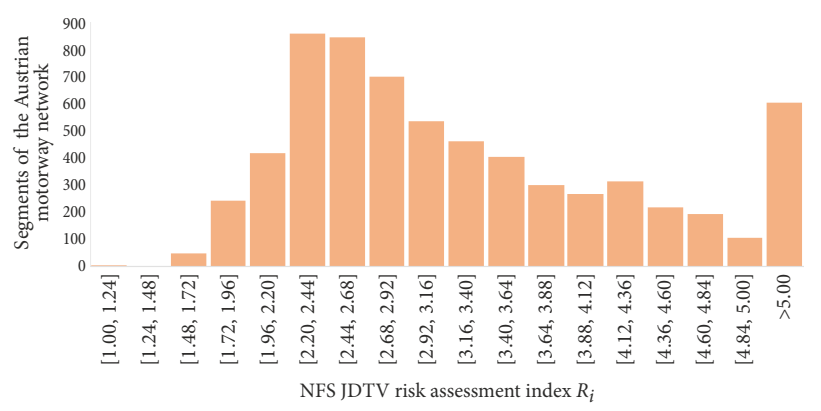

Figure 5. Risk assessment index $R_{i}$, in relation to actual traffic statistics from the Austrian motorway and road network, with: HFS = main lane, NFS = side lane, JDTV = annual average traffic density for cars, and JDTLV = annual average traffic density for trucks

The influence of the pavement grip on the rating of the vehicle impact risk is achieved via the fragility curves discussed in the above, and as shown in Figures 7(a) to 7(d). An increase of this influence from level $a=3$ to $a=1$ indicates the sensitivity to this parameter. For $a=1$ the course of the fragility curve is linear. This reduction of factor $a$ leads to a shift of the ranking values by at least 0.5 to the higher risk range. The proportion of those in class $>5$ is also significantly increased. This indicates the sensitivity of factor $a$ with regards to the assessment. The risk of impact increases for the combined traffic flow, but the prevalent risk level in the network lies in the region of 2.25 to 3.25. The influence of the pavement ruts on the risk rating of the vehicle impact is described (as in the case of grip) through the fragility curves. In Figures 8(a) to $8(\mathrm{~d})$, the increase of the influence from level $a=3$ to $a=1$ causes a shift of the ranking values by at least 0.75 classes to the higher risk range. The proportion of traffic situations in class $>5$ is again increased for all four traffic situations considered. 
a)

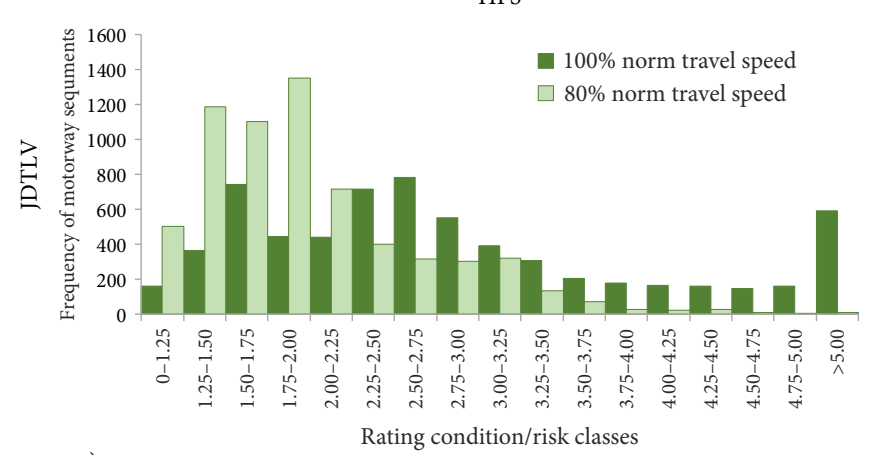

c)

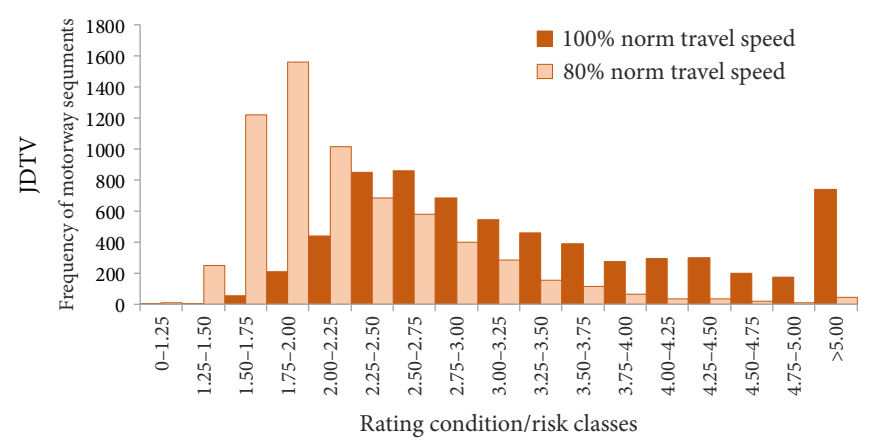

b)

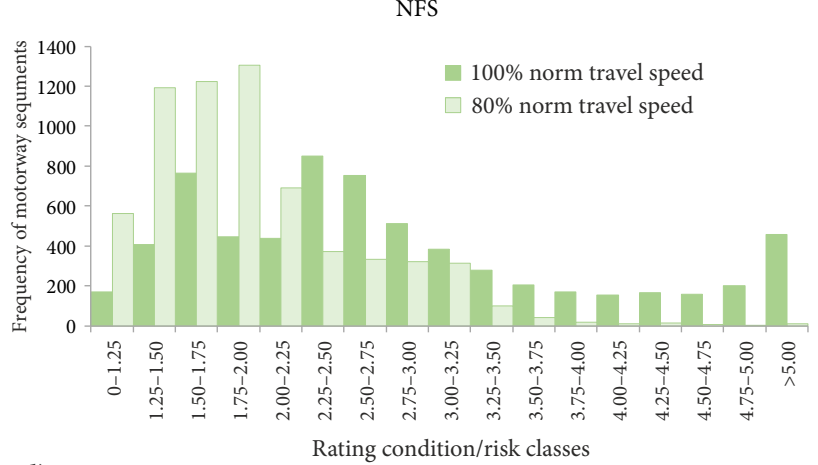

d)

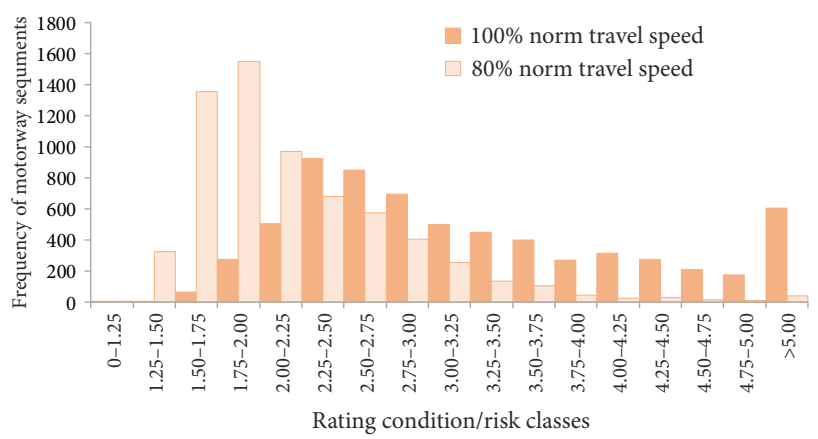

Figure 6. Risk assessment index $\mathrm{R}_{\mathrm{i}}$, in relation to actual traffic statistics from the Austrian motorway and road network, with emphasis on travel speed

a)

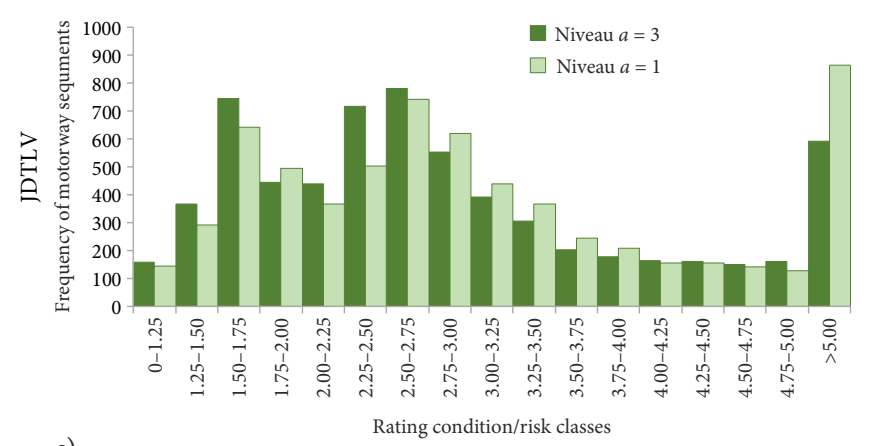

c)

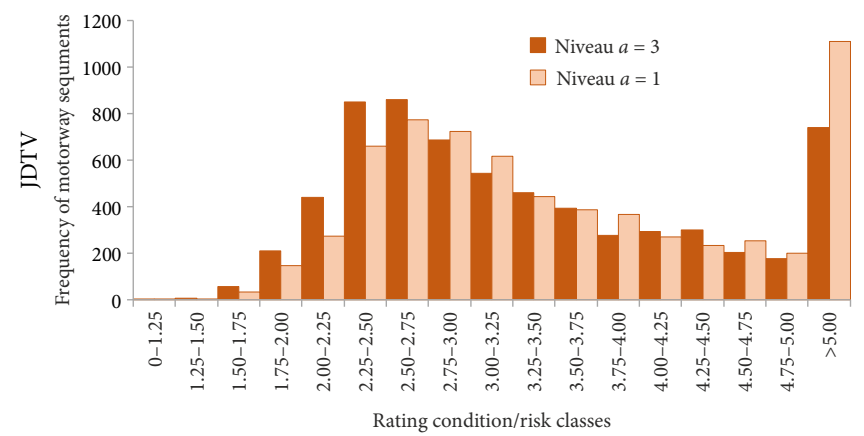

b) NFS

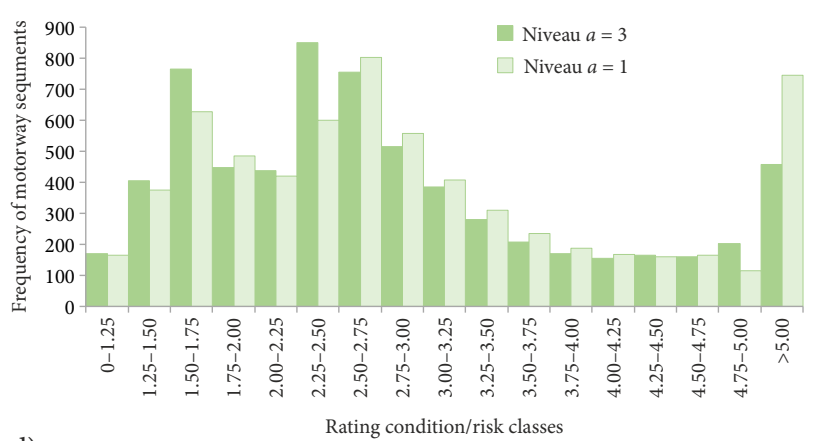

d)

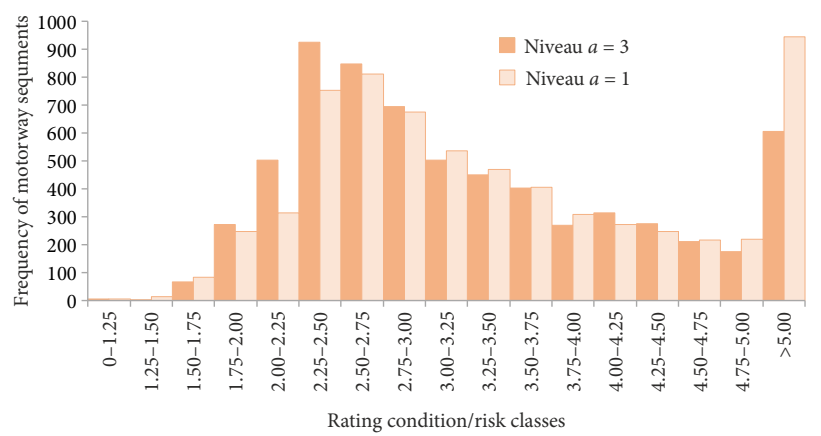

Figure 7. Risk assessment index $R_{i}$, in relation to actual traffic statistics from the Austrian motorway and road network, with emphasis on pavement grip properties 
a)

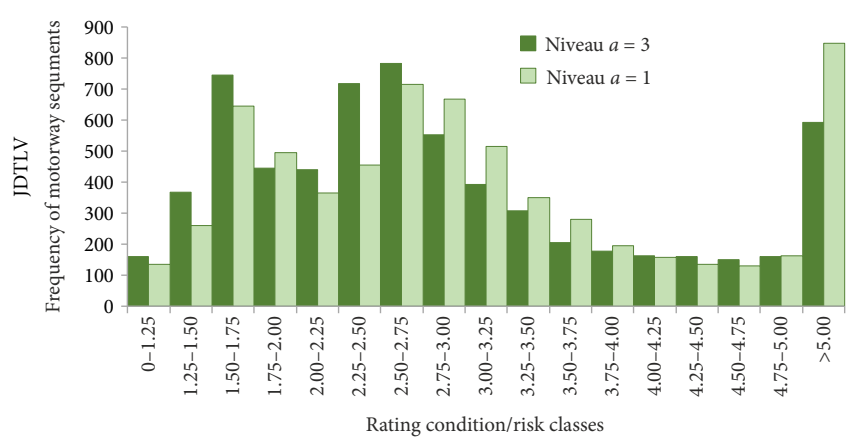

c)

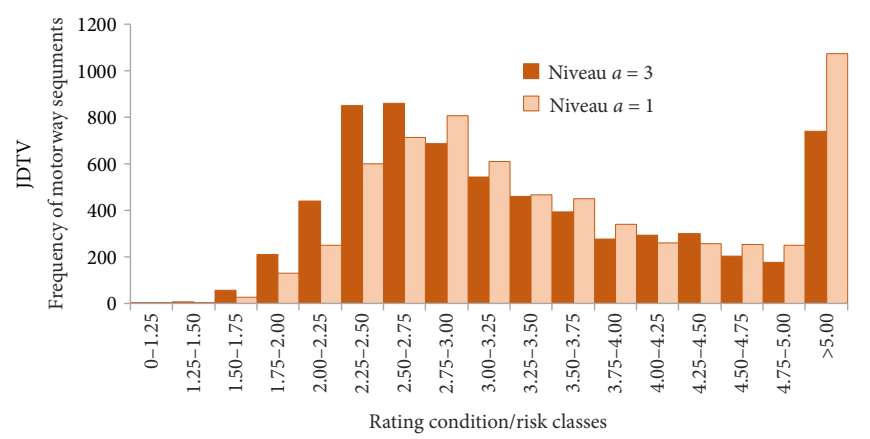

b)

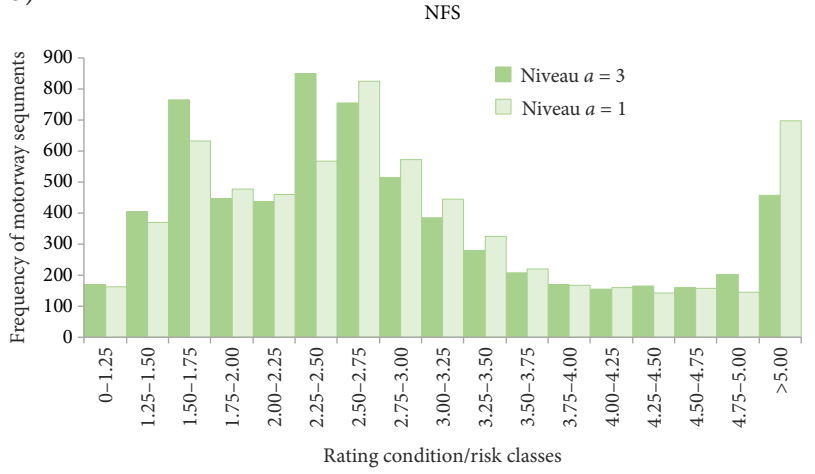

d)

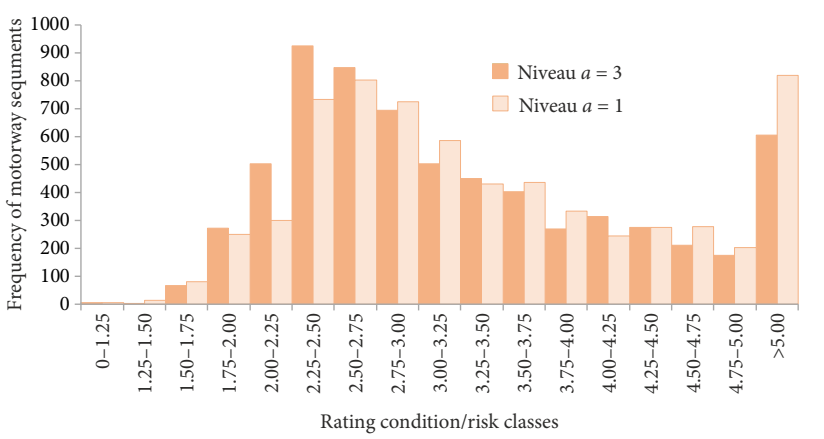

Figure 8. Risk assessment index $R_{i}$, in relation to actual traffic statistics from the Austrian motorway and road network, with emphasis on pavement ruts

a)

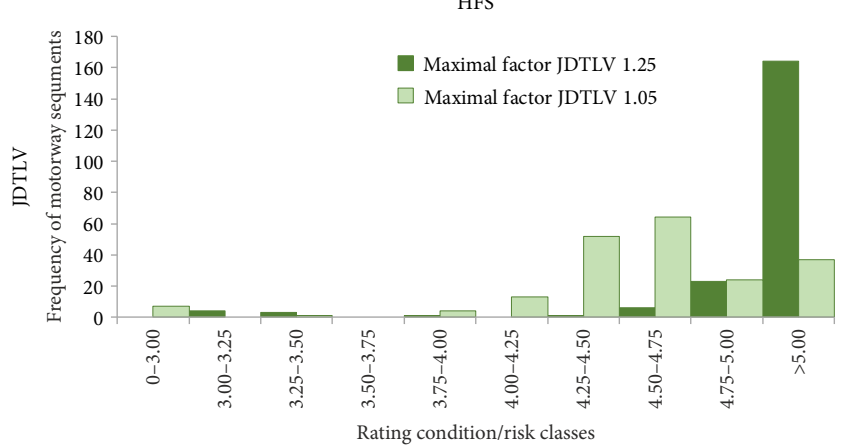

c)

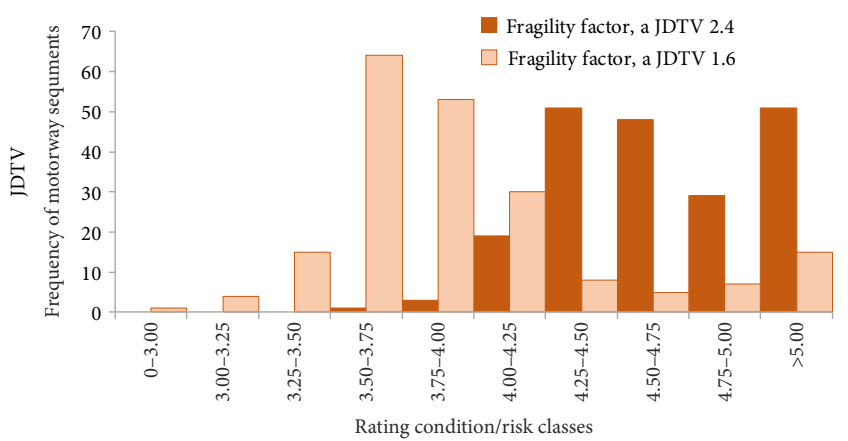

b)

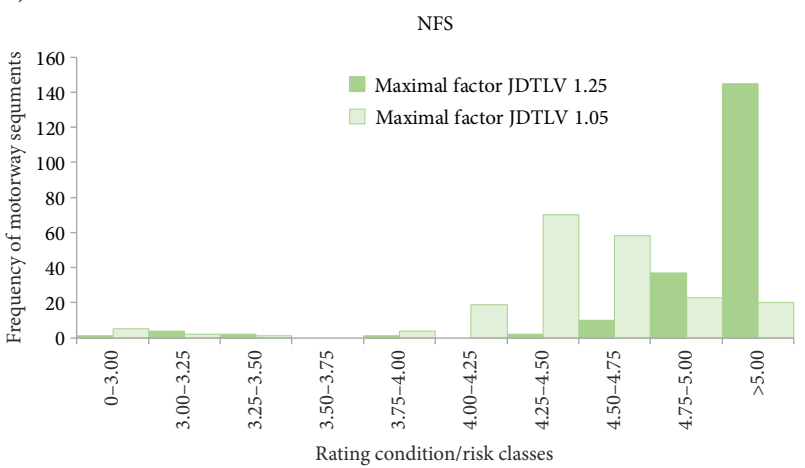

d)

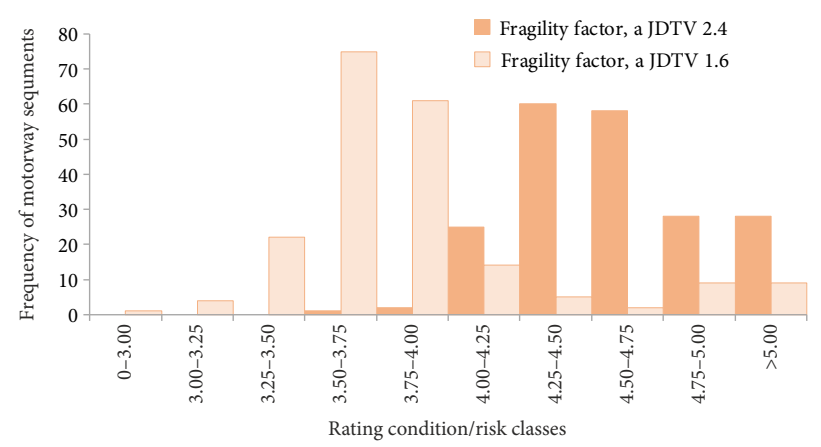

Figure 9. Risk assessment index $R_{i}$, in relation to actual traffic statistics from the Austrian motorway and road network, variation in the fragility factors of JDTV and JDTLV with: HFS = main lane, NFS = side lane, JDTV = annual average traffic density for cars, and JDTLV = annual average traffic density for trucks 
Figures 9(a) to 9(d) show the assessment indices for the impact risk on the crash barriers for a segment of a motorway. In this case, the differentiation between a twolane and a three-lane pavement is analysed. As seen from the diagrams, the three-lane layout causes a reduction of one class on average and thus, as expected, a significant reduction of the concentrated population in the class 5 . The high sensitivity between the risk ratings and the fragility curve characteristics ( $a$ factor) is particularly evident from the respective sequence of distributions. For a factor $\alpha=$ 1.25 in the JDTLV group $88 \%$ and $73 \%$ of the cases are disqualified with a rating $>5.0$, compared to only $17 \%$ and $11 \%$ for $\alpha=1.05$, as seen respectively in Figures 9(a) and 9(b). These differences are more moderate but still evident for the JDTV group. For an $\alpha$ factor of 2.4 the disqualified cases reach $25 \%$ and $15 \%$, compared to $7 \%$ and $5 \%$ for $\alpha=$ 1.6 (Figures 9(c) and 9(d), respectively). Markedly, for the JDTV group and for a factor $\alpha=2.4$ virtually all cases are in a class 4 or higher, while for $\alpha=1.6$ less than a third ranks as high.

\section{Conclusions}

In this paper it has been shown to be useful for the evaluation of the effects of traffic on the restraint systems to assume a reference configuration with a failure probability $p_{f}=10^{-6}$. This failure probability assumes a typical limit state function $G=R-S$, where $R$ is the resistance of the restraint systems, and $S$ the impact effect on the restraint systems by a departing vehicle. To this end the influences of the longitudinal and the transverse gradient, and the curvature are evaluated by physical driving dynamics. The surface condition of the road surface, such as grip, and extend of damage are evaluated through appropriately adjusted fragility curves, on the basis of rating and empirical values.

The developed method allows for an automated risk assessment according to the traffic composition, the occupancy level of the lanes, the JDTV and JDTLV values, the surface measurement data retrieved by mapping vehicles, and the alignment, in accordance with the rating system developed in RVS 13.03.51 (FVS, 2013).

The automated risk assessment is not an indicator for the health state of the restraint system, but indicates which components of the furniture and installed infrastructure are at increased risk of impact due to the traffic situation, the alignment characteristics, and the road surface conditions, and therefore require special attention during inspections or in the event of a necessary replacement.

The application of the method on the infrastructure network of a road operator allowed the efficient risk assessment and mitigation, i.e. reduction of risk ranking by two classes. This was achieved by the following measures: (a) $20 \%$ speed reduction, (b) renewal of the surface grip, and (c) repair of road ruts.

The fragility curves used in this method were derived on the basis of expert knowledge and in some instances national guidelines and standards. They can be adapted, verified, and extended during the implementation of the proposed tool. Besides, they also create awareness for the more informed and accurate evaluation of the components under study. They also generate considerations and a basis for examination of the influencing variables and, as a consequence, the risk of collisions due to vehicle lane departures.

Finally, the findings can be summarised as follows:

- In this research project, an efficient analytical decision tool has been developed together with an infrastructure owner for the assessment and the intervention planning of the road equipment using elements of Probabilistic Safety Concepts (PSC), whereby the inputs are routing and traffic properties belonging to the action side of the PSC.

- Combination of traffic dynamic parameters and routing characteristics to a closed analytical solution for a RVS based rating of impacts on road equipment is shown.

- The analytical formulation comprises fragility curves for the incorporation of the condition rating of road elements, such as the pavement conditions, in physical based information from traffic volume, curve radii, vehicle speed, etc.

- In addition, the probabilistic based analytical decision tool allows an individual adjustment of the acceptable reliability level, the acceptable risk and thereby the remaining technical service life by the infrastructure operator.

- The developed approach also shows handling of input parameters with significant uncertainties in an efficient, user-friendly, and rational manner

- The used fragility curve approach has the advantage of supporting weak information e.g. from expert knowledge that can be improved with increasing time and the continuous use of the tool.

- The model shown in this article is extensible for additional properties and can be transferred with relative flexibility to other systems based on large databases.

\section{Acknowledgements}

The authors acknowledge the support of the Interreg project ATCZ 190 "SafeBridge" and the COST TU1406 action, awarded by the European Commission.

\section{Author contributions}

AS and TM conceived the study and were responsible for the design and development of the data analysis. AS, TM and $\mathrm{CH}$ were responsible for data collection and analysis. AS and TM were responsible for data interpretation. AS and PS wrote the first draft of the article. DF was responsible for the review and control of analyses and interpretation. 


\section{Disclosure statement}

The authors have no competing financial, professional, or personal interests from other parties.

\section{References}

American Association of State Highway and Transportation Officials (AASHTO). (2018). Manual for bridge evaluation (3rd ed.). Washington, DC.

Ang, A. H. \& Tang, W. H. (2007). Probability concepts in engineering planning and design. Wiley.

Autobahnen- und Schnellstraßen-Finanzierungs-Aktiengesellschaft (ASFINAG). (2015). Planungshandbuch Straße - Bau Technische Richtlinie [Planning Manual Road - Construction Technical Guideline]. Austria's Motorways and Expressways Financing Corporation, Vienna.

Benbow, E., \& Wright, A. (2017). Summary of deliverables 1 and 2 of the PREMIUM project and the work required to achieve the recommendations. In Conference of European Directors of Roads (CEDR).

ERA-NET ROAD. (2012). Asset service condition assessment methodology (ASCAM) deliverable No. 4 "Inventory road equipment management practices".

Federal Ministry of Transportation, Building and Urban Development. (2011). Richtlinie zur Nachrechnung von Strassenbrücken im Bestand [Guideline for the recalculation of existing road bridges]. Department for Road Construction.

International Organization for Standardization (ISO). (2010). ISO-13822: Basis for design of structures - Assessment of existing structures. Geneva.

Kim, J. J. (2018). Development of empirical fragility curves in earthquake engineering considering nonspecific damage information. Advances in Civil Engineering, 6209137. https://doi.org/10.1155/2018/6209137

Linstone, H. A., \& Turoff, M. (1975). The Delphi method - techniques and applications. Addison-Wesley.

Meyer, M. A., \& Booker, J. M. (2001). Eliciting and analyzing expert judgment: a practical guide. Society for Industrial and Applied Mathematics. https://doi.org/10.1137/1.9780898718485

Nederlands Normalisatie Instituut. (2011). NEN 8700 (nl) - Assessment of existing structures in case of reconstruction and disapproval - basic rules.

Österreichische Forschungsgesellschaft Straße-Schiene-Verkehr (FSV). (1998a). RVS 05.04.33: Ausführung, Abnahme, Betrieb, Instandhaltung - Verkehrslichtsignalanlagen [Execution, acceptance, operation, maintenance or traffic light signal systems]. Vienna.

Österreichische Forschungsgesellschaft Straße-Schiene-Verkehr (FSV). (1998b). RVS 05.04.34: Abnahme- und Prüfprotokoll Verkehrslichtsignalanlagen [Acceptance and test protocol for traffic light signal systems]. Vienna.

Österreichische Forschungsgesellschaft Straße-Schiene-Verkehr (FSV). (2005a). RVS 08.23.05: Straßenausrüstung - Leitschienen aus Stahl [Road equipment - steel guard rails]. Vienna.

Österreichische Forschungsgesellschaft Straße-Schiene-Verkehr (FSV). (2005b). RVS 08.23.06: Straßenausrüstung - Leitwände aus Beton [Road equipment - Concrete guide walls]. Vienna.

Österreichische Forschungsgesellschaft Straße-Schiene-Verkehr (FSV). (2007a). RVS 05.02.31: Leiteinrichtungen, Rückhaltesysteme - Anforderungen und Aufstellung [Guiding equipment, restraint systems - Requirements and erection]. Vienna.
Österreichische Forschungsgesellschaft Straße-Schiene-Verkehr (FSV). (2007b). RVS 08.09.02: Oberflächenschutz von Stahl und Aluminium [Surface protection of steel and aluminium]. Vienna.

Österreichische Forschungsgesellschaft Straße-Schiene-Verkehr (FSV). (2009a). RVS 05.02.11: Verkehrszeichen und Ankündigungen - Anforderungen und Aufstellungen [Traffic signs and advertisements - Requirements and specifications]. Vienna.

Österreichische Forschungsgesellschaft Straße-Schiene-Verkehr (FSV). (2009b). RVS 08.23.01: Straßenausrüstung - Verkehrszeichen Prüfungen (Prüfverfahren - Zulas-sung/Abnahme) [Road equipment - Traffic sign tests]. Vienna.

Österreichische Forschungsgesellschaft Straße-Schiene-Verkehr (FSV). (2009c). RVS 08.23.07: Straßenausrüstung - VLSA [Road equipment - Traffic light signal systems]. Vienna.

Österreichische Forschungsgesellschaft Straße-Schiene-Verkehr (FSV). (2009d). RVS 08.10.04: Brückenausrüstung - Leiteinrichtungen - ersetzt durch LB Infrastruktur [Bridge equipment - guidance devices]. Vienna.

Österreichische Forschungsgesellschaft Straße-Schiene-Verkehr (FSV). (2013a). RVS 12.01.12: Standards in der betrieblichen Erhaltung von Landesstraßen [Standards in the operational maintenance of national roads]. Vienna.

Österreichische Forschungsgesellschaft Straße-Schiene-Verkehr (FSV). (2013b). RVS 13.03.51: Überwachung, Kontrolle und Prüfung von Kunstbauten - Wegweiserbrücken [Monitoring, control and inspection of engineering structures - signpost bridges]. Vienna.

Österreichische Forschungsgesellschaft Straße-Schiene-Verkehr (FSV). (2018). Standardisierte Leistungsbeschreibung Verkehr und Infrastruktur LB-VI [Standardised performance descriptions for traffic and infrastructure]. Vienna.

Schneider, J. (2006). Introduction to safety and reliability of structures. IABSE.

Sjögren, L., His, A., Edvardsson, K., Wennström, J., Haider, M., Casse, C., Van Geem, C., Benbow, E., Wright, A., Žnidarič, A., \& Kokot, D. (2013). Overall road asset performance. ERANET ROAD. Retrieved from https://www.diva-portal.org/ smash/get/diva2:814340/FULLTEXT01.pdf

Spielhofer, R. D. (2014). Collaborative project FP7-285119. Advanced and cost effective road infrastructure construction, management and maintenance. Deliverable D 4.2 Monitoring of Road Inventory.

Spielhofer, R., Oldfield, M., Britton, C., Levine, H., Brozek, B., Weninger-Vycudil, A., Lepert, P., Mladenovic, G., Le Bars, G., Pohu, J., \& Litzka, H. (2015). Cross-asset risk assessment (XARA) - Risk framework and modelling specifications, Deliverable D1.2, Deliverable D2.1. In Conference of European Directors of Roads (CEDR).

Spielhofer, R. D., Osichenko, D., Leal, D., Benbow, E., Wright, A., \& Morgan, P. (2016). Identifying the key characteristics for noise barriers condition measurements - Deliverable D1d and D2d. In Conference of European Directors of Roads (CEDR).

Spielhofer, R. D., Osichenko, D., Leal, D., Benbow, E., \& Wright, A. (2017a). Identifying the key characteristics for vehicle restraint system condition measurements - Deliverable D1a and D2a. In Conference of European Directors of Roads (CEDR).

Spielhofer, R. D., Osichenko, D., Leal, D., Benbow, E., \& Wright, A. (2017b). Identifying the key characteristics for road sign condition measurements - Deliverable D1b and D2b. In Conference of European Directors of Roads (CEDR). 
Strauss, A., Wendner, R., Bergmeister, K., Reiterer, M., \& Horvatits, J. (2011). Monitoring and influence lines based performance indicators. Beton- und Stahlbetonbau, 106(4), 231-240. https://doi.org/10.1002/best.201100003

Strauss, A., Vidovic, A., Zambon, I., Dengg, F., \& Matos, J. C. (2016). Performance indicators for roadway bridges. In Maintenance, Monitoring, Safety, Risk and Resilience of Bridges and Bridge Networks - Proceedings of the 8th International Conference on Bridge Maintenance, Safety and Management, IABMAS 2016 (pp. 965-970). Taylor \& Francis Group.
Troutbeck, R. (Ed.). (2013). Transportation research circular E-C172: Roadside safety design and devices - International workshop. Roadside Safety Design Committee.

Weninger-Vycudil, A., Litzka, J., Schiffmann, F., Lindenmann, H. P., Haberl, J., Scazziga, I., Rodriguez, M., Hueppi, A., \& Jamnik, J. (2009). Maintenance backlog estimation and use. Road Eranet. 